\title{
Original \\ The Influence of Zingiber Officinale Roscoe on the Histological Changes of Soft Palatal Mucosa in Streptozotocin-induced Type 3 Diabetes Rat Model
} Article

\author{
Fatma Adel Saad
}

Oral Biology Department, Faculty of Dentistry, Future University in Egypt

\begin{abstract}
Background: Zingiber officinale Roscoe presents valuable outcomes in some neurodegenerative diseases.

Objective: This study aimed to evaluate Zingiber oil extract efficacy in the regression of Type3 diabetes mellitus (T3DM) induced in rat model.

Methodology: 28 adult male albino rats were divided into four equal groups: Control-ve group received no injections; Control+ve group received a single bilateral intra-cerebroventricular (ICV) injection of sterile $0.9 \%$ saline, T3DM group received a single bilateral ICV injection of streptozotocin $(3 \mathrm{mg} / \mathrm{kg})$ dissolved in sterile $0.9 \%$ saline; Zingiber treated group five weeks after ICV- STZ, received orally $100 \mathrm{mg} / \mathrm{kg} /$ day Zingiber oil extract for two months. Soft palate oral mucosal sections were processed for H\&E, fluorescence staining (using thioflavin-T dye) and immunohistochemical (using anticaspase-3 and anti-VEGF antibodies) examination.

Results: Both control groups were almost identical. Some T3DM sections histopathologically displayed inflammatory signs represented by cloudy swelling of keratinocytes, nuclear degenerative signs, apparently increased apoptotic keratinocytes, subepithelial degeneration, chronic inflammatory infiltrates, congested dilated blood vessels, hyperplasia and dilatation of palatal glandular acini and excretory duct. Irregular and decreased palatal fungiform papillae with few vacuolated taste cells were illustrated. Comparing to control groups, significant strong diffuse thioflavin-T fluorescence in oral epithelium, palatal acini, endothelium of blood vessels along with subepithelial amyloid deposits in some T3DM specimens were detected. Likewise, caspase-3 immunoreactivity in oral epithelial and connective tissue cells significantly increased in T3DM group. Similarly, significant positivity to VEGF in oral epithelium and in the significantly increased blood vessels in wall thickness and distribution were exhibited in T3DM sections. All T3DM results were significantly restored in Zingiber group except for the low significant decrease of caspase-3 reactivity in this group.

Conclusions: It was concluded that Zingiber oil extract was an appropriate selected approach to ameliorate the possible T3DM associated peripheral tissue insults but most probably in a higher dose or prolonged supplementation.
\end{abstract}

Received: 26 October 2019, Accepted: 27 November 2019

Key Words: $\beta$-amyloid, soft palate, streptozotocin, type 3 diabetes, Zingiber.

Corresponding Author: Fatma Adel Saad, PhD, Oral Biology Department, Faculty of Dentistry, Future University in Egypt, Tel.: +20 1223739140, E-mail: femy76@hotmail.com

ISSN: 1110-0559, Vol. 43, No.2

\section{INTRODUCTION}

Type 3 diabetes mellitus (T3DM) is a metabolic disease. Several studies have shown that the deficits in the utilization of glucose by the brain eventually led to the cognitive dysfunction. Previous studies elucidated that the impairment of both insulin/insulin-like growth factor signaling and cerebral glucose utilization preceded the cognitive impairment supporting the concept that type 3 diabetes is an insulin-resistant brain state. Moreover, it could be regarded as a brain disorder that has composite features of T1DM (insulin deficiency) and T2DM insulin resistance ${ }^{[1,2]}$. The main oral manifestations in T3DM are usually due to improper oral hygiene and xerostomia. These all triggered a number of dental problems including caries, periodontal disease, gingivitis, halitosis and a progressive destruction of teeth ${ }^{[3]}$. On the other hand, T3DM pathology can be observed in non-neural tissues so that oxidative damage and accumulation of the amyloid protein have been noted ${ }^{[4]}$.

Amyloid is a nonspecific term for diverse chemical structures as beta- 2 microglobulin, keratin, some hormones and serum amyloid fibril proteins. In particular, all these structures appeared histologically as homogeneous eosinophilic substances ${ }^{[5]}$. "Amyloidosis" which encompasses a wide spectrum of inflammatory diseases characterized by systemic or localized extracellular aggregates of insoluble fibrillar proteins which impair the normal organ function ${ }^{[6]}$. These aggregates are formed due to its imbalanced production and degradation and are regarded to be toxic. Amyloid beta protein $(A \beta)$ is normally generated as a nontoxic soluble peptide, essential for cell survival and possesses important physiological functions ${ }^{[7]}$. Peripherally, $\mathrm{A} \beta$ has been proved to be primarily produced by platelets 
and other cells such as skeletal muscle cells ${ }^{[8]}$. Misfolded amyloid peptide with cross-beta structure was produced from the intracellular cleavage of the amyloid precursor protein (APP) by proteolytic enzymes ${ }^{[9]}$. This cleavage gives rise to the transformation of $\beta$-amyloid peptide monomers from random coil to $\beta$-amyloid protein oligomers that seed the formation of fibrils and plaques ${ }^{[10,11]}$. Soluble oligomers are more toxic than the plaques. $A \beta$ peptide can be considered as the initiating pathological factor in T3DM and associated with neurodegenerative changes ${ }^{[11,12]}$.

Zingiber officinale Roscoe is generally considered as a safe herbal medicine according to the FDA's Safe (GRAS) list ${ }^{[13]}$. It has been utilized in Asian traditional medicine and has been applied to several diseases such as joint and muscle pain, toothaches, gingivitis, metabolic dysfunction and cancer with clinical evidence. Approximately 400 kinds of constituents in Zingiber have been disclosed involving carbohydrates, lipids, terpenes, and phenolic compounds ${ }^{[13-15]}$. Zingiber extract could protect nerve cells and may have the potentiality for the treatment of $\mathrm{T} 3 \mathrm{DM}^{[16]}$. For the reason that little is known about the oral mucosal changes in T3DM, this work aimed to explore the influence of Zingiber extract oil on the T3DM-associated alterations in the soft palatal mucosa of rats.

\section{MATERIALS AND METHODS}

\subsection{Ethical Clearance}

This study was carried out according to the regulations of the Research Ethics Committee (FDASU-REC) of the Faculty of Dentistry, Ain Shams University, Egypt.

\subsection{Animals}

Twenty eight adult male albino rats, weighed 200-220 gm and aged 5-6 months, were housed under controlled temperature, humidity, dark-light cycle and under the supervision of specialized veterinarian since their housing till getting rid of sacrificed bodies. The rats were kept under good ventilation and adequate stable diet consisting of fresh vegetables, dried bread and tap water throughout the experimental period (13 weeks).

\subsection{Experimental Design}

After one week acclimatization period, the animals were randomly divided into four groups (seven rats each) as follows:

Group I (Control -ve): The rats had no injections.

Group II (Control +ve): The rats were anesthetized then received a single bilateral intra-cerebroventricular (ICV) injection of sterile $0.9 \%$ saline $(4.5 \mu \text { per injection site })^{[17]}$.

Type 3 diabetes was induced in group III and IV by intracerebral injection of streptozotocin (STZ) (Sigma, St. Louis, MO, USA).

Group III (T3DM group): The rats were anesthetized then received a single bilateral (ICV) injection of STZ (3 $\mathrm{mg} / \mathrm{kg}$ total dose) dissolved in sterile $0.9 \%$ saline (4.5 $\mu$ l per injection site $)^{[17,18]}$.
Group IV (Zingiber treated group): Five weeks after intracerebral injection of STZ ${ }^{[19]}$, the animals were treated with a daily dose of $100 \mathrm{mg} / \mathrm{kg}$ Zingiber extract oil (Sigma, St. Louis, MO, USA) by oral gavages for two months ${ }^{[16]}$.

\subsection{Procedure of Intracerebral Injection}

Rats were anaesthetized using $80 \mathrm{mg} / \mathrm{kg}$ ketamine. Animal's head was placed and fixed in the stereotaxic device (David Kopf Instruments - Germany) ${ }^{[20]}$ and the scalp was incised to locate the bregma. The STZ solution was injected $1.0 \mathrm{~mm}$ posterior and $1.0 \mathrm{~mm}$ lateral to the bregma and $2.5 \mathrm{~mm}$ deep to the skull surface of each hemisphere using a 30-gauge needle affixed to a Hamilton microliter syringe. The injections were completed within 3 minutes and the needle was withdrawn slowly from the brain as reported in other studies ${ }^{[21,2]}$

By the end of experimental periods, 13 weeks from the beginning of the experiment, animals of all groups were sacrificed by intracardiac administration of anesthetic overdose (sodium thiopental $80 \mathrm{mg} / \mathrm{kg} \mathrm{BW}$ ) ${ }^{[22]}$. The brain tissues (cortex and hippocampus) were excised and the soft palatal mucosa was dissected free using a surgical scalpel. Getting rid of sacrificed rats' bodies was done according to the ethical committee rules in the incinerator of Ain Shams University Hospital.

\subsection{Histopathological Examination}

\subsubsection{Brain Tissue}

The excised brain tissues were fixed in $4 \%$ paraformaldehyde for 24 hours and embedded in paraffin. Then it was sliced into $5 \mu \mathrm{m}$ sections using a section cutter (Leica, Germany). Sections were stained with haematoxylin and eosin as well as Congo red ${ }^{[23]}$.

\subsubsection{Oral Mucosa of the Soft Palate}

The dissected specimens were immediately fixed for 48 hours in $10 \%$ formaldehyde solution then washed, dehydrated in increasing concentrations of alcohol and lastly embedded in paraffin. $4-5 \mu \mathrm{m}$ serial sections were stained with haematoxylin and eosin ${ }^{[24]}$.

For histopathological examination, all the stained sections were examined using the light microscope (Olympus ${ }^{\circledR}$ BX 60, Tokyo, Japan).

\subsection{Fluorescence Staining}

The sections of soft palatal oral mucosa from each group were stained by thioflavin-T (Sigma, St. Louis, MO, USA) to identify amyloid fibrils aggregation. $0.5 \%$ of thioflavin-T in $0.1 \mathrm{~N} \mathrm{HCl}$ solutions was incubated with the tissue sections after deparaffinization, rehydration and washing of these sections in PBS. For each section, a drop of thioflavin T solution was placed on the slide that was next kept for $15 \mathrm{~min}$ in a humidity chamber. The slides were then rinsed for $5 \mathrm{~min}$ in deionized water, kept in deionized water and coverslipped with aquamount. Thioflavin-T stain was examined under a standard dark field ultraviolet fluorescence microscope 
(Olympus ${ }^{\circledR}, \mathrm{BX} 41$, Tokyo, Japan). Thioflavin-T fluoresced if bound to amyloid fibrils giving a bright yellow-green fluorescence while in the absence of amyloid aggregates, the dye faintly fluoresced ${ }^{[25]}$.

\subsection{Immunohistochemical Examination}

Immunolabeling for detection of caspase-3 and vascular endothelial growth factor (VEGF) using anti-caspase-3 (rabbit polyclonal antibody) and anti-VEGF (VG1 mouse monoclonal antibody) respectively were performed. 4-5 $\mu \mathrm{m}$ paraffin-embedded tissue sections were mounted on positively charged microscope slides and were then deparaffinized. Blockage of the endogenous peroxidase activity was done by the immersion of the sections in methanol with $0.3 \%$ hydrogen peroxide then washed in phosphatebuffered saline (PBS). Antigen retrieval for anti-VEGF antibody in some sections and for anti-caspase- 3 antibody in other sections was performed in oven (60 min, Trypsin $\mathrm{pH}$ 7.9). Subsequently, the tissue sections were incubated at $4{ }^{\circ} \mathrm{C}$ with primary antibodies anti-VEGF (dilution 1:400, overnight) and anti-caspase-3 active form (dilution 1:100, overnight) followed by washing of the sections twice in PBS. Thereafter, the sections were incubated with biotinylated secondary universal antibody and with streptavidin-biotinperoxidase complex (Dako) at room temperature in order to bind the primary antibodies according to the manufacturer's protocol. Peroxidase activity was visualized by immersing tissue sections in diaminobenzidine substrate (DAB) to attain the desired brown color. At last, the sections were counterstained with Mayer's hematoxylin and coverslipped. Immunohistochemical examinations were performed using a light microscope (Olympus ${ }^{\circledR}$ BX 60, Tokyo, Japan). Both caspase- 3 and VEGF expression was confirmed by the presence of cytoplasm \&/or nuclear brown staining in epithelial and connective tissue cells ${ }^{[26,27]}$.

\subsection{Statistical Analysis}

Data obtained from the analysis of thioflavin-T staining, caspase-3 and VEGF immunoexpression in the soft palate oral mucosa were statistically described in terms of mean \pm standard deviation $( \pm \mathrm{SD})$ median and range. Data were analyzed using Statistical Package for Social Science software computer program version 23 (SPSS, Inc., Chicago, IL, USA). One way Analysis of variance (ANOVA) and Tukey were used for comparing data. $P$ value less than 0.05 was considered statistically significant.

\section{RESULTS}

\subsection{Histopathological Results}

\subsubsection{Histopathological Results of Brain Tissue}

The histopathological results of brain tissues in both control-ve and control+ve groups were almost identical. H\&E staining of brain tissue sections revealed regularly arranged neurons with normal structure and big round regular nuclei (Figure 1a). On the contrary, the brain tissue of T3DM specimens displayed amyloid plaques that were investigated and detected using Congo red staining.
Red - orange stained amyloid deposits (Figure 1b), as well as the positively stained endothelial walls of the thickened cerebral blood vessels (Figure 1c), were demonstrated.

\subsubsection{Histopathological Results of the Soft Palate Oral Mucosa}

Group I(C-ve): Inthe softpalate, theoral surfaceis covered by orthokeratinized mucosa. An underlying thick glandular layer was gradually thinning towards the posterior part of the soft palate. Subjacently, a dense collagen layer named as the palatal aponeurosis was separated from the pseudostratified ciliated columnar nasal epithelium by an elastic lamina. The muscular element occupied only the posterior third of the palatal tissues (Figure 2a). The Orthokeratinized mucosa of oral surface was divided into three zones. Most lateral zone had a relatively smooth epithelial surface with deep and regular rete pegs. No or occasional intraepithelial taste buds were seen in this zone (Figure 2b). Medial to this zone, the very regular flatter and smooth intermediate zone revealed no rete pegs but few scattered intra-epithelial taste buds were detected (Figure 2c). The most medial central zone illustrated irregularity in both epithelial surface and rete pegs and exhibited numerous fungiform papillae with taste buds (Figure 2d). Oral palatal epithelium appeared as a less dense and thin keratinized stratified squamous epithelium. It was formed of large keratinocytes with bulky cytoplasm and was often binucleated or with multiple nuclear lobes particularly in the basal and spinous cell layers. Noticeable intensely stained keratohyalin granules occurred in the stratum granulosum. The lamina propria was composed of a loose vascular connective tissue continuous with the thin connective tissue septa surrounding the underlying palatine glands. These glands were mixed mostly mucous with few serous demilunes. The transition from the palatine glands to the stratified squamous epithelium via an excretory duct was noted (Figures 2b, 2c and 2d).

Group II (C+ve): showed almost similar results to those of the control-ve group with few mildly congested blood vessels (Figure 2e).

Group III (T3DM): Inflammatory signs were observed in some specimens of this group represented by cloudy swelling in basal, spinous and granular cell layers of the oral epithelium with apparently pale eosinophilic cytoplasm. Cytoplasmic vacuolation was also revealed in some basal cells while other cells showed nuclear pyknosis, karyorrhexis, vacuolation and karyolysis. The keratohyaline granules of few granular cells were clumped with increased basophilia. Obvious detachment of keratin with corrugated surface was frequently evident. Apparent increase of clear cells was seen besides some apoptotic keratinocytes in basal and suprabasal cell layers. Underlying lamina propria illustrated subepithelial degeneration, irregularly oriented collagen fibers with apparent reduced density and some inflammatory cells (Figure 2f). Basilar epithelial hyperplasia and obvious chronic inflammatory and giant cells infiltrates were noted in the lamina propria of some specimens. Congested and dilated blood vessels were also found with extravasted blood cells. Moreover, hyperplasia and dilatation 
of the submucous glandular acini were detected with dilated excretory duct. The palatal fungiform papillae manifested an irregular appearance with a reduction in their distribution, and vacuolation of few taste cells (Figures $2 g$ and $2 h$ ).

Group IV (Zingiber): Restoration of these pathologic changes was detected in this group. Most of the examined $H \& E$ sections displayed similar features to the control groups in both oral epithelium and lamina propria. But some inflammatory cells, few congested dilated blood vessels with extravasated blood cells and dilated glandular acini were seen in some areas (Figure 3a). Furthermore, few areas in few specimens appeared with some pathologic changes such as an increase of clear cells in epithelium and detachment of keratin. Likewise, degenerative connective tissues areas, less dense and irregularly arranged collagen fibers along with few inflammatory infiltrates could be observed in the lamina propria (Figure 3b).

\subsection{Fluorescence Staining and Statistical Results}

Group I (C-ve) and Group II (C+ve): Both groups demonstrated faint to mild thioflavin-T fluorescence in the basal and parabasal cell layers of the soft palatal oral epithelium with insignificant difference $(P$ value $=0.9)$. Keratin was positively stained for thioflavin-T. The underlying lamina propria and submucosa of both groups displayed insignificant different faint to mild fluorescence in basal and cellular membranes of the palatal glandular mucous acini $(P$ value $=0.39)$ as well as in the endothelial lining of blood vessels $(P$ value $=0.69)$ (Figures 4a, 4b and Figure 7).

Group III (T3DM): Comparing to control groups, a significantly increased fluorescence $(P$ value $<0.001)$ appeared as a diffuse strong intracellular fluorescence in the basal, parabasal and some suprabasal cell layers besides the distinct fluorescence of the cellular membranes of the thickened soft palatal epithelium in some sections (Figure $4 \mathrm{c}$ and Figure 7 ). Other sections presented faint fluorescence of the apparently unchanged epithelium in thickness while a statistically significant $(P$ value $<0.001$ ) strong intracellular and membranous fluorescence of the palatine acinar cells was also seen (Figure $4 d$ and Figure 7). The underlying lamina propria showed numerous subepithelial strongly stained amyloid deposits with thioflavin-T in some areas (Figures 4c, 4d). Moreover, the significantly increased blood vessels in thickness and distribution exhibited a significant (Pvalue $<0.001)$ strong thioflavin-T staining in their vascular walls (Figure 4e and Figure 7).

Group IV (Zingiber): This group revealed a significantly decreased fluorescence ( $P$ value $<0.001$ ) comparing to T3DM group but with a significant increase compared to control groups ( $P$ value $<0.001)$. Mild to moderate diffuse intracellular fluorescence in the epithelial cells of some specimens was noticed. Likewise, the endothelium of the significantly decreased blood vessels in distribution and thickness comparing to T3DM group as well as the acinar cells of the palatal glands showed moderate thioflavin- $T$ fluorescence (Figure 4f and Figure 7).

\subsection{Immunohistochemical and Statistical Results}

\subsubsection{Immunohistochemical and Statistical Results for Caspase-3 Immunoreactivity}

Group I (C-ve) and Group II (C+ve): The soft palate oral epithelium of both control groups revealed a statistically insignificant reactivity. Mild diffuse cytoplasmic immunoreactivity to caspase-3 in some basal and superficial epithelial cells $(P$ value $=0.79)$ occurred with a negative nuclear reaction. Moreover, few connective tissue cells included fibroblasts in the lamina propria presented mild cytoplasmic immunoreactions $(P$ value $=0.9)$ (Figures 5a, 5b and Figure 8).

Group III (T3DM): Comparing to control groups, some specimens elucidated a statistically significant ( $P$ value $<0.001)$ immunostaining heterogeneity in the oral epithelium including the soft palate fungiform papillae. This heterogeneity varied from mild to moderate diffuse cytoplasmic reaction with a focally distributed strong reactivity across the different epithelial layers and in the vacuolated intraepithelial taste bud cells with a negative nuclear reaction. Furthermore, immunoreacted nuclear brown granules in the apparently increased apoptotic keratinocytes (colloid bodies or Civatte) were detected. The lamina propria also illustrated significantly increased caspase-3 positive fibroblasts and inflammatory cells $(P$ value $<0.001)$ comparing to control groups (Figures 5c, 5d and Figure 8).

Group IV (Zingiber): Besides the significant increase of caspase-3 expression in this group compared to control groups ( $P$ value $<0.001)$, the oral epithelia and taste bud cells of some soft palatal sections when related to T3DM group displayed a low significant decreased immunoreactivity $(P$ value $=0.02$ ). This was illustrated as a moderate diffuse cytoplasmic reactivity that appeared strong in superficial epithelial cells with an apparent mild nuclear reaction in few epithelial and taste cells. Simultaneously, an apparent decrease of the positive apoptotic keratinocytes was also observed. Additionally, a low significant decrease $(P$ value $=0.018$ ) of the positive inflammatory and connective tissue cells were evident (Figure $5 \mathrm{e}$ and Figure 8). Yet, some specimens exhibited features simulating those of control groups.

\subsubsection{Immunohistochemical and Statistical Results for VEGF Immunoreactivity}

Group I (C-ve) and Group II (C+ve): The soft palate oral epithelial cells of both groups apparently showed nuclear and mild diffuse cytoplasmic reaction to VEGF in some basal and suprabasal epithelial cells with insignificant difference $(P$ value $=0.9)$ (Figures $6 \mathrm{a}$ and $6 \mathrm{c})$. While for the endothelial lining of the few noted capillaries in the lamina propria of both, it groups was positively reacted to VEGF with insignificant differences in microvascular density $(P$ value $=0.75)$ and wall thickness $(P$ value $=0.99)$ (Figures 6b and 6d). 
Group III (T3DM): Comparing to control groups, a significantly ( $P$ value $<0.001)$ increased moderate nuclear and diffuse heterogeneou cytoplasmic reaction to VEGF was found in the palatal oral epithelium, fungiform epithelial cells and some intraepithelial taste cells in some specimens. Furthermore, a mild VEGF immunoreactivity was noticed in the cloudy swollen and apoptotic keratinocytes (Figures 6e, 6f and Figure 9). VEGF was expressed in the endothelium of the significantly increased blood vessels in distribution $(P$ value $<0.001)$ and wall thickness $(P$ value $<0.001)$ (Figure $6 \mathrm{~g}$ and Figure 9).
Group IV (Zingiber): A significant increase of VEGF expression in this group compared to control groups ( $P$ value $<0.001)$ was detected. In contrast, a significantly decreased mild to moderate nuclear and diffuse cytoplasmic immunoreaction ( $P$ value $<0.001$ ) was perceived compared to T3DM group in some epithelial cells as well as in the taste bud cells. Apparent increase of the negatively reacted epithelial cells was also seen. In relation to T3DM group, the endothelial VEGF expression in most specimens was observed in the significantly decreased blood vessels in distribution $(P$ value $<0.001)$ and wall thickness $(P$ value $<0.001)$ (Figure 6h and Figure 9).
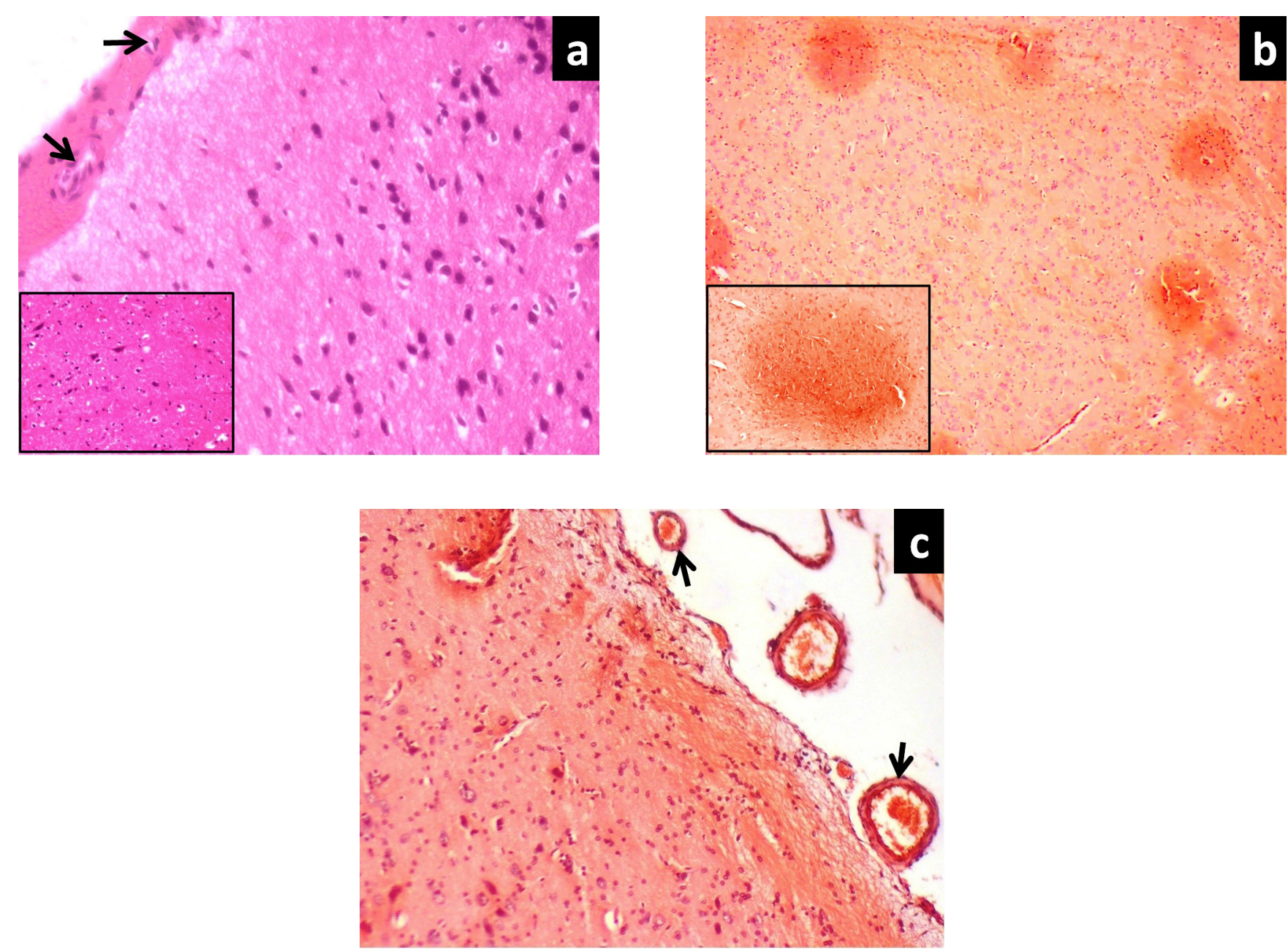

Fig. 1: Photomicrograph of brain tissue sections: A: Control brain tissue with normal alignment and structure of neurons and blood vessels (arrows) (H\&E, X100); B: Brain tissue of T3DM group presented amyloid plaques (Congo red, X100; Inset: X200 ); C: T3DM brain tissue showing cerebral thickened blood vessels (arrows) by amyloid deposits (Congo red, X200). 


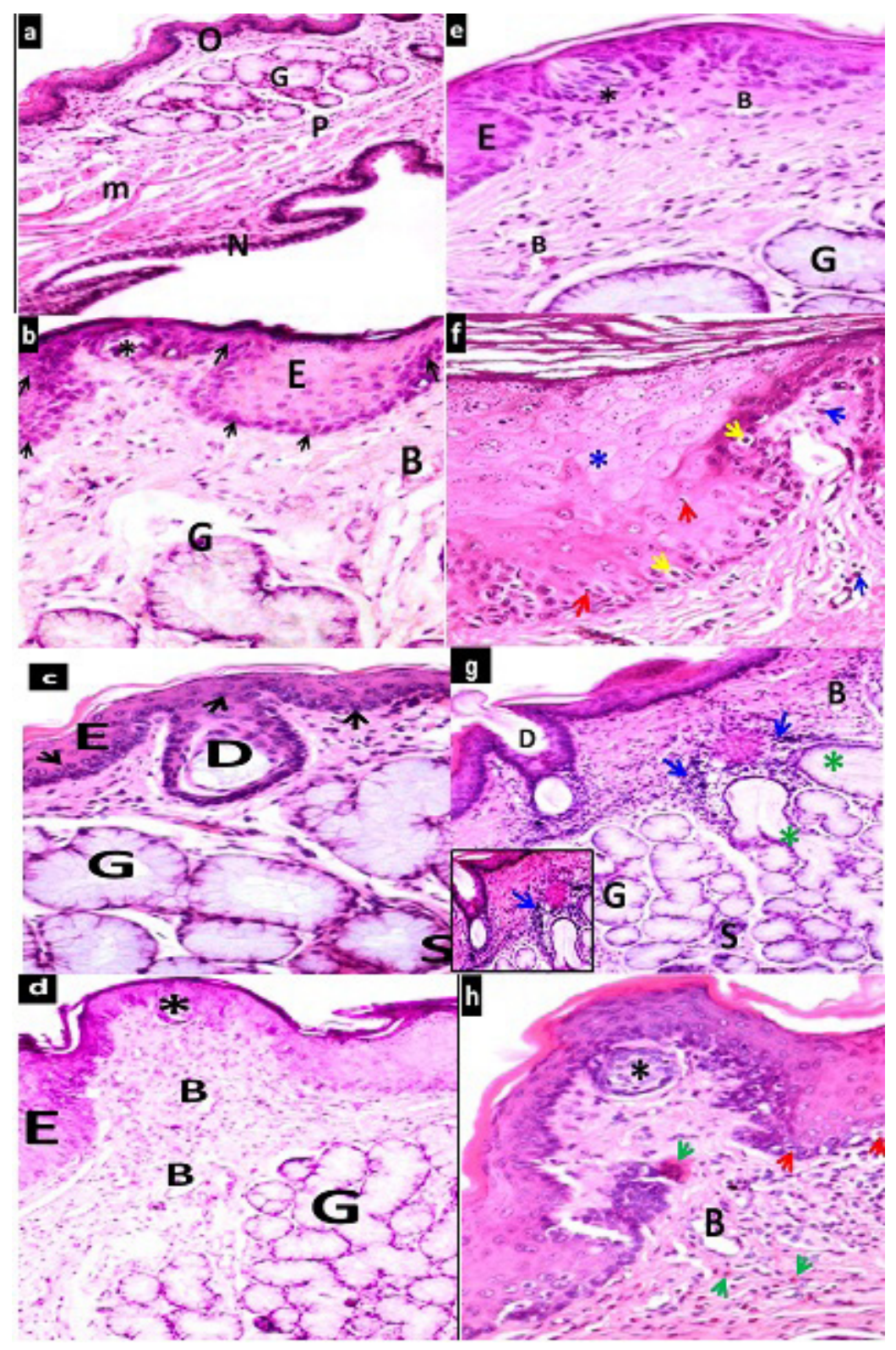

Fig. 2: Photomicrographs of rat soft palatal oral mucosa; C-ve group (I) showing (a) oral mucosa (O), glandular layer (G), palatal aponeurosis (P), pseudostratified ciliated columnar nasal mucosa $(\mathrm{N})$ and muscle $(\mathrm{m})(\mathrm{H} \& \mathrm{E}, \mathrm{X} 100)$, (b) outer zone of soft palatal oral mucosa with keratinized stratified squamous epithelial covering, some binucleated keratinocytes, lamina propria continuous with connective tissue septa surrounding palatine glands (H\&E, X200), (c) intermediate zone with no rete pegs, epithelium continuous with lining of excretory duct, mixed mostly mucous palatine glands with few serous demilunes (H\&E, X200), (d) soft palatal central zone with palatal fungiform papilla and taste bud (H\&E, X100). C+ve group (II) showing (e) palatal fungiform papilla with taste bud and few blood vessels (H\&E, X200). T3DM group (III) showing (f) cloudy swelling of epithelial cells, cytoplasmic and nuclear vacuolations in some cells, apparently increased clear cells, apoptotic basal and suprabasal keratinocytes, detached keratin, subepithelial degeneration, irregularly oriented collagen fibers and some inflammatory cells (H\&E, X200), (g) apparent intense inflammatory cells infiltrates, hyperplasia and dilatation of both glandular acini and excretory duct (H\&E, X100; Inset: X200), (h) basilar epithelial hyperplasia, irregularly shaped palatal fungiform papillae, few vacuolated taste cells and congested dilated blood vessels with extravsation (H\&E, X200). Epithelium (E), glands (G), blood vessel (B), excretory duct (D), serous demilune (S), binucleation (black arrows), taste bud (black asterisk), cloudy swelling (blue asterisk), clear cells (yellow arrows), apoptotic keratinocyte (red arrow), inflammatory cells (blue arrow), dilated acini (green asterisks), extravasted blood cells (green arrows). 

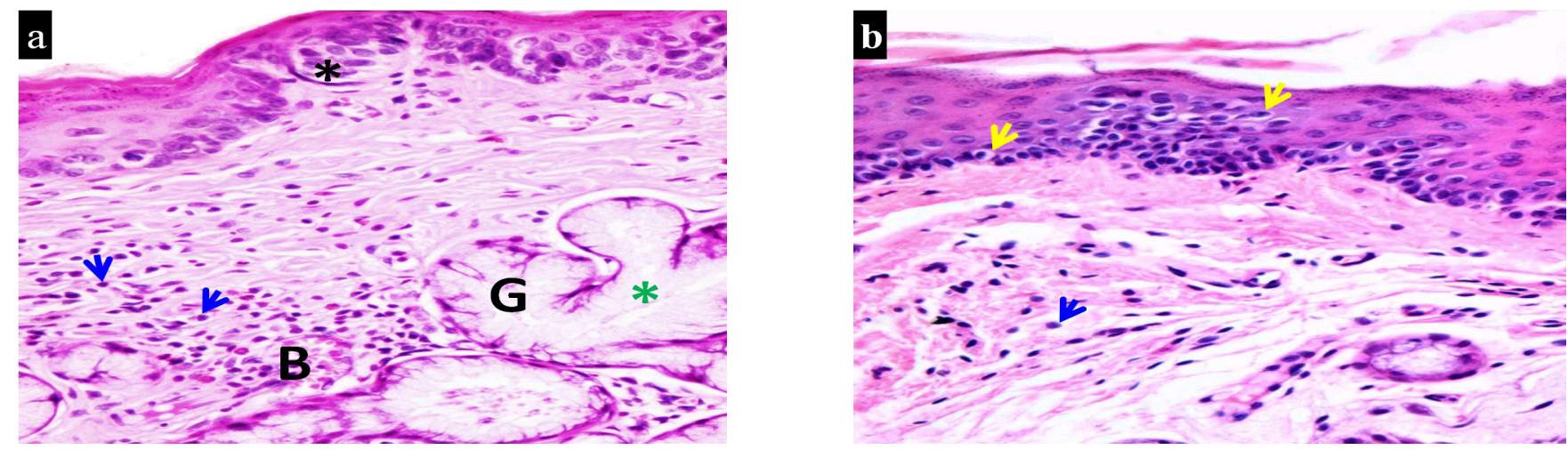

Fig. 3: Photomicrographs of rat soft palatal oral mucosa of Zingiber group (IV) showing (a) almost normal epithelium and lamina propria but with some inflammatory cells, extravasated blood cells and dilated glandular acini (H\&E, X200), (b) apparent increase of clear cells, detached keratin, degenerative connective tissues areas and few inflammatory cells (H\&E, X200). Taste bud (black asterisk), palatine glands (G), blood vessel (B), inflammatory cells (blue arrows), dilated acini (green asterisk) and clear cells (yellow arrows).
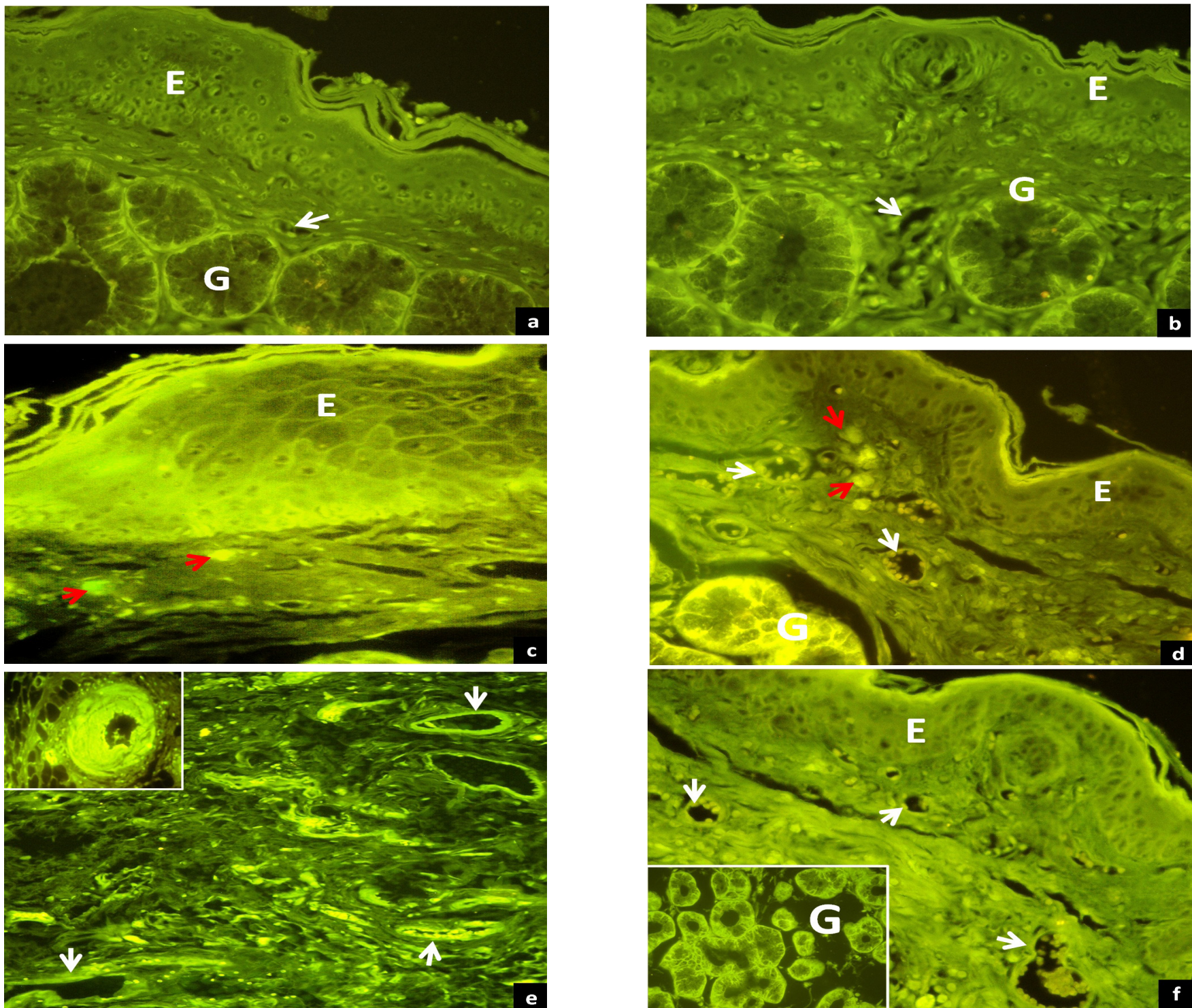

Fig. 4: Photomicrographs of thioflavin-T fluorescence staining of soft palatal oral mucosa in rats showing positively stained keratin. C-ve group (I) showing (a) faint to mild fluorescent epithelium, basal and cellular membranes of glandular acini as well as blood vascular walls (original magnification x400). C+ve group (II) showing (b) faint to mild fluorescence similar to control group (original magnification $\mathrm{x} 400$ ). T3DM group (III) revealing (c) diffuse intracellular strong fluorescence in basal and some suprabasal cell layers and some strongly fluorescent subepithelial amyloid deposits (original magnification $\mathrm{x} 400$ ), (d) some sections displaying faint epithelial fluorescence of apparently unchanged epithelium in thickness, strong fluorescent subepithelial amyloid deposits and glandular acini (membranous and inracellular) (original magnification x400), (e) strong fluorescent endothelium of the apparently increased blood vessels in thickness and distribution (original magnification x200, Inset: x200). Zingiber group (IV) showing (f) Mild to moderate diffuse intracellular epithelial fluorescence, Moderate fluorescence of vascular endothelium in the apparently decreased blood vessels and of glandular acinar cells in some specimens (original magnification $\mathrm{x} 400$, Inset: $\mathrm{x} 400$ ). Epithelium (E), palatine glands (G), blood vessels (white arrows) and amyloid deposits (red arrows) 

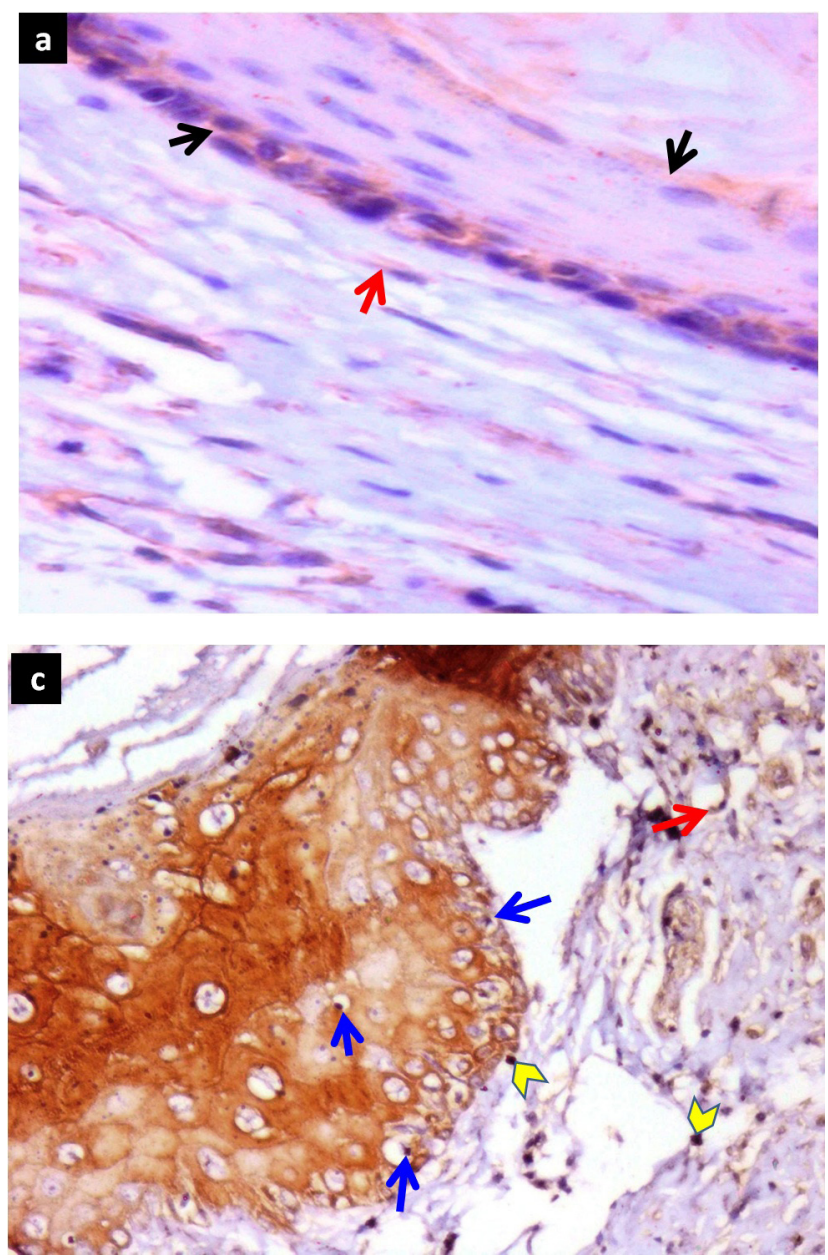
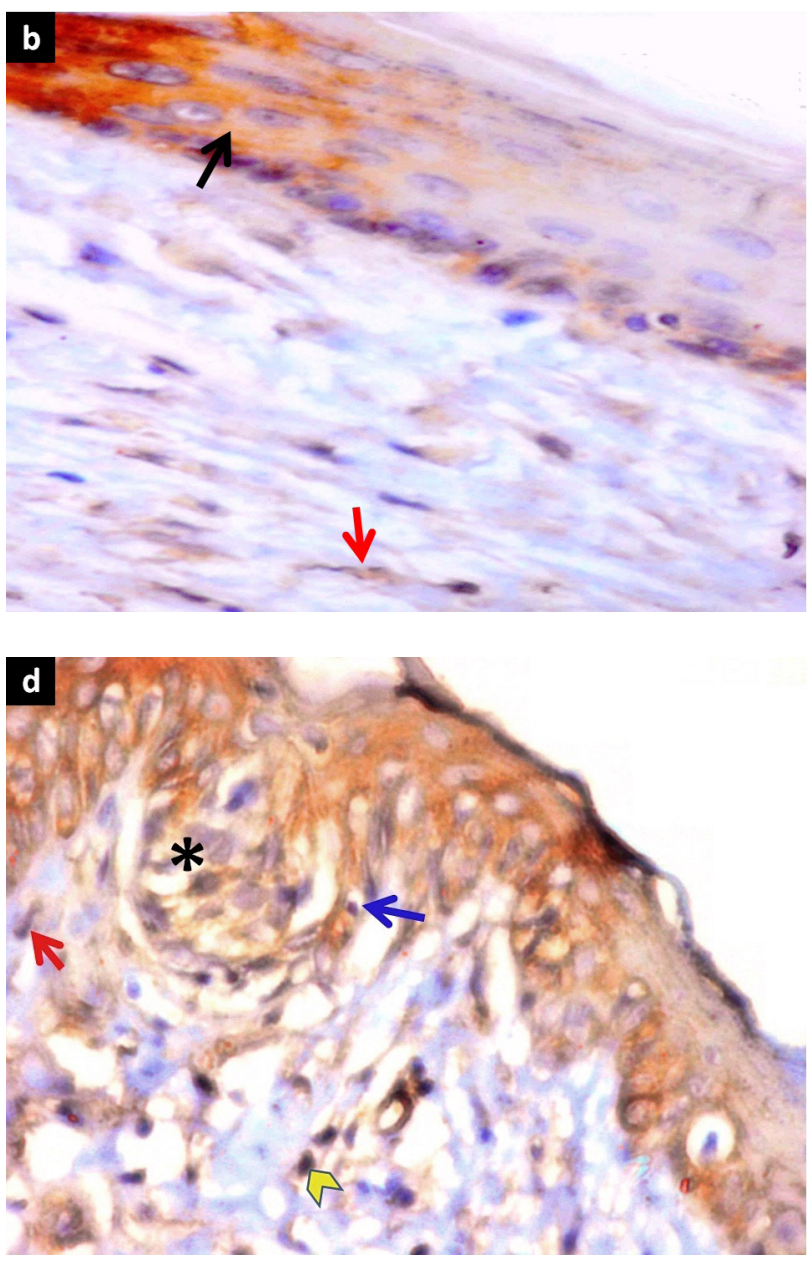

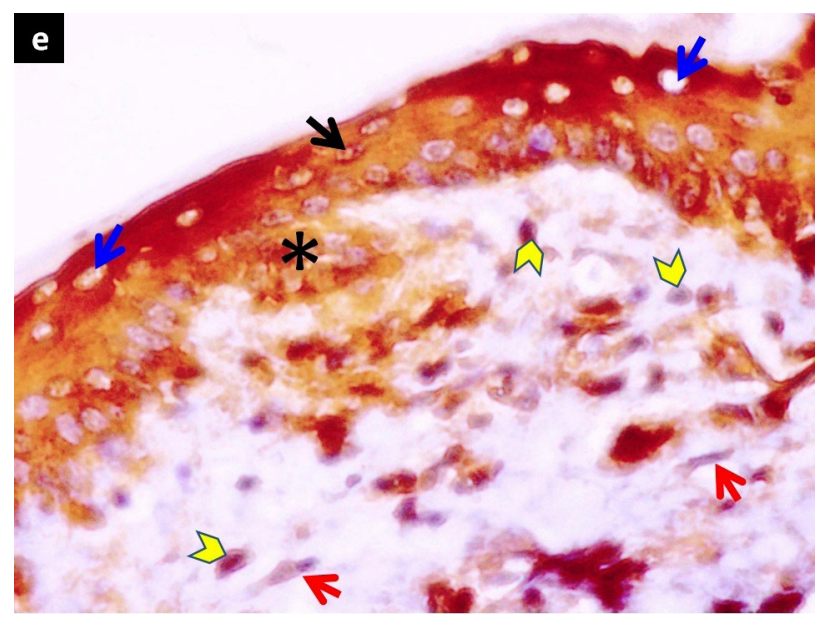

Fig. 5: Photomicrographs of rat soft palatal oral mucosa showing the immunohistochemical reaction to anti-caspase-3, C-ve group (I) showing (a) apparent mild cytoplasmic positivity with negative nuclear reaction of basal and most superficial epithelial cells (black arrows) as well as some fibroblasts in lamina propria (red arrow)(original magnification $\mathrm{x} 400$ ). C+ve group (II) showing (b) similar reaction in some epithelial cells (black arrow) and fibroblasts (red arrow) (original magnification $\mathrm{x} 400$ ). T3DM group (III) displaying (c) mild to moderate diffuse cytoplasmic reaction with focal strong reactivity across epithelium (original magnification $\mathrm{x} 200$ ), (d) palatal fungiform papilla with cytoplasmic reaction involved intraepithelial vacuolated taste bud (original magnification $\mathrm{x} 400$ ), (c , d) apparent increase of caspase-3-positive apoptotic keratinocytes (blue arrows), fibroblasts (red arrows) and inflammatory cells (yellow arrow heads). Zingiber group (IV) showing (e) moderate diffuse cytoplasmic reaction of fungiform taste bud cells and oral epithelium with strong cytoplasmic reaction in some cells of the most superficial cell layers. Mild nuclear reaction in few epithelial (black arrow) and taste cells (asterisk), apparent decrease of apoptotic keratinocytes (blue arrows), few positive fibroblasts (red arrows) and apparent increase of caspase-3 positive inflammatory cells (yellow arrow heads) (original magnification x200, Inset; $x 400)$. 

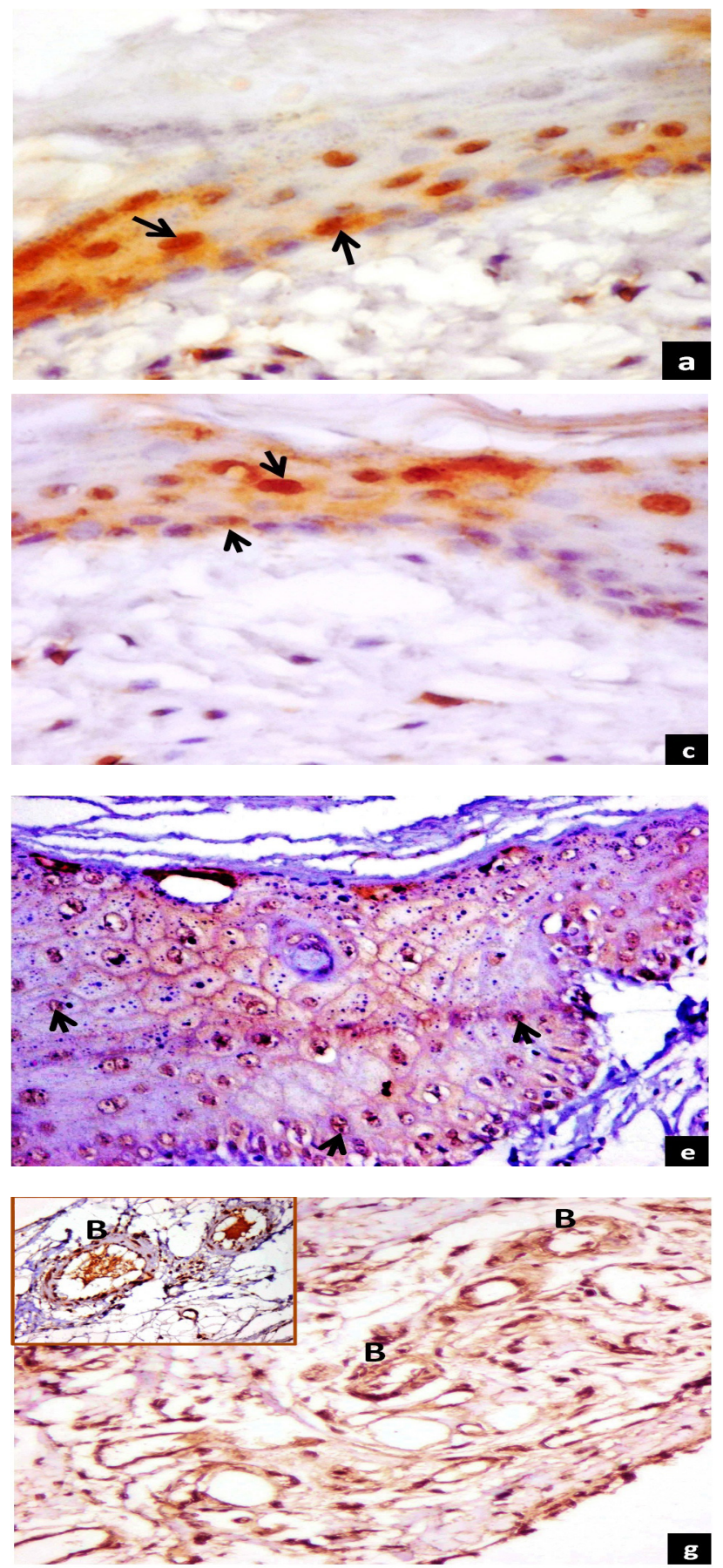
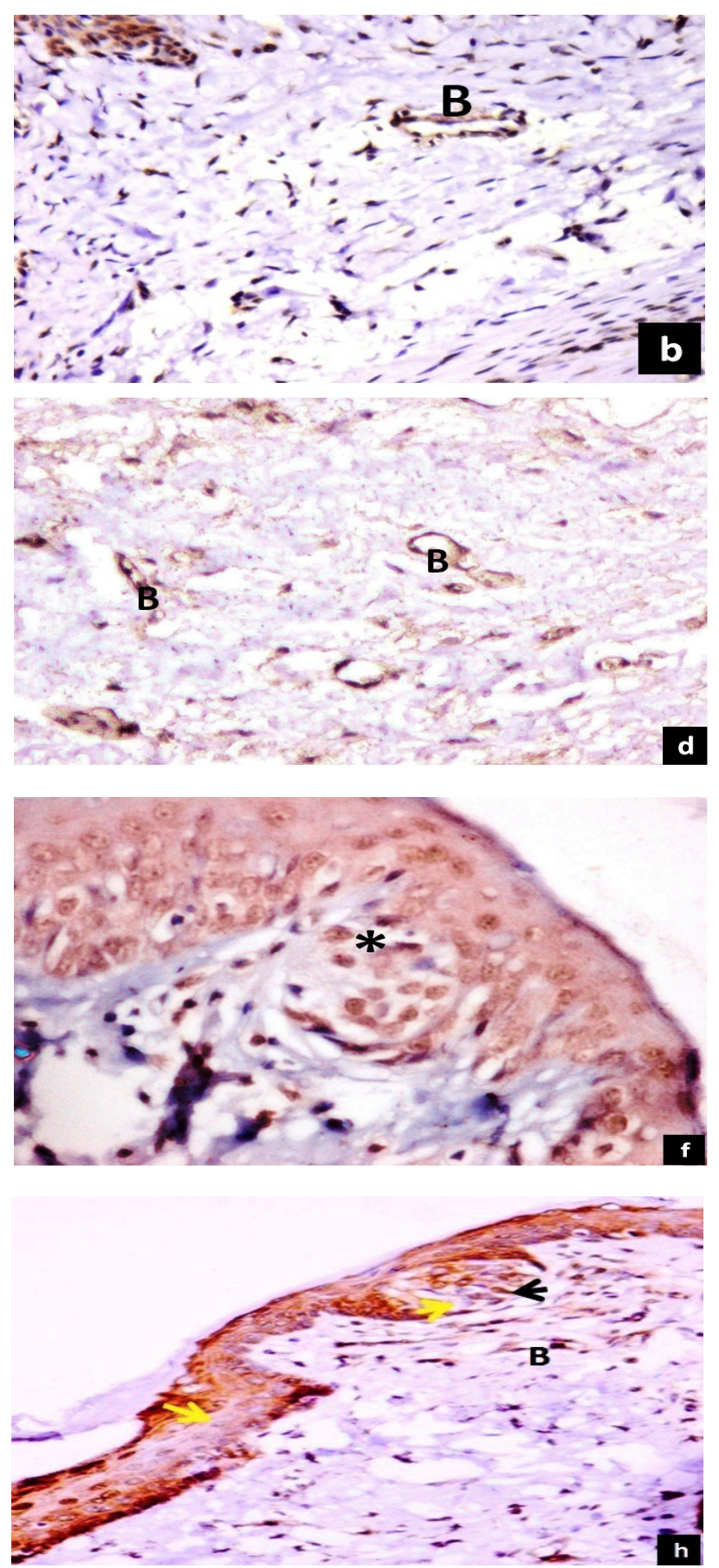

Fig. 6: Photomicrographs of rat soft palatal oral mucosa showing the immunohistochemical reaction to anti-VEGF; C-ve group (I) showing (a) mild diffuse cytoplasmic reaction in the basal and some areas of suprabasal cell layers, mild to moderate nuclear reaction in some epithelial cells (original magnification $\mathrm{x} 400$ ), (b) positively reacted endothelial lining of few capillaries in the lamina propria of C-ve group (original magnification x200). C+ve group (II) revealing (c) reactivity in some epithelial cells like C-ve group (original magnification x400), (d) positively stained endothelium of blood capillaries simulated those of C-ve group (original magnification x200). T3DM group (III) displaying (e) mild cytoplasmic reaction with focal areas of moderate diffuse cytoplasmic reactivity across the epithelial cell layers with almost mild positive nuclear reaction (original magnification x200), (f) palatal fungiform papilla with mild diffuse cytoplasmic and nuclear reaction of epithelial cells with nuclear reactivity in some intraepithelial taste bud cells (original magnification $\mathrm{x} 400$ ), (g) VEGF positive endothelium of the apparently increased and thickened blood vessels was seen (original magnification x200), Inset: x400). Zingiber group (IV) showing (h) mild to moderate diffuse cytoplasmic and nuclear reaction in epithelial and taste bud cells, negatively reacted cells, VEGF expressed endothelium in the apparently decreased blood vessels in distribution and thickness (original magnification x200). Blood vessel (B), duct (D), positively reacted epithelial nuclei (black arrows), , taste bud (black asterisk), negatively reacted cells (yellow arrows). 
Thioflavin fluorescence (Epithelium)

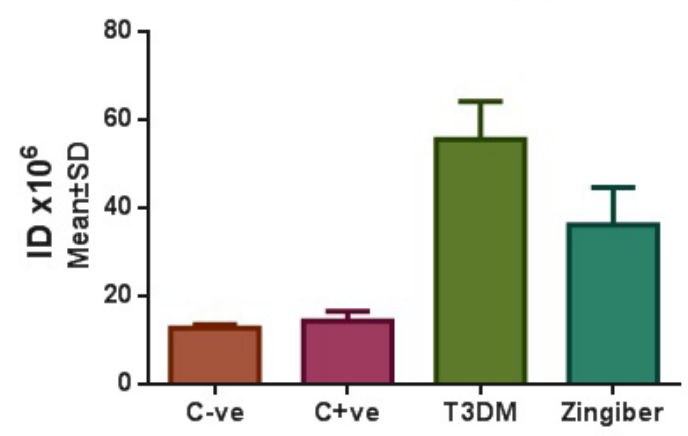

Thioflavin fluorescence (Galnds)

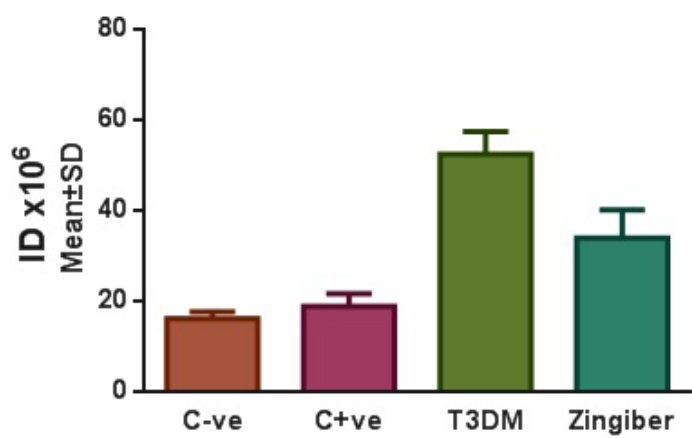

Thioflavin fluorescence (blood vessels)

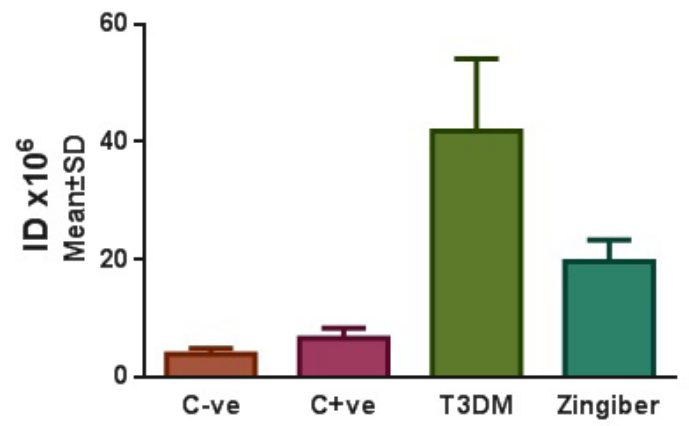

Fig. 7: Bar charts showing mean \pm SD of thioflavin-T fluorescence (Integrated density $x 10^{6}$ ) in epithelium, palatine glands and blood vessels among all studied groups
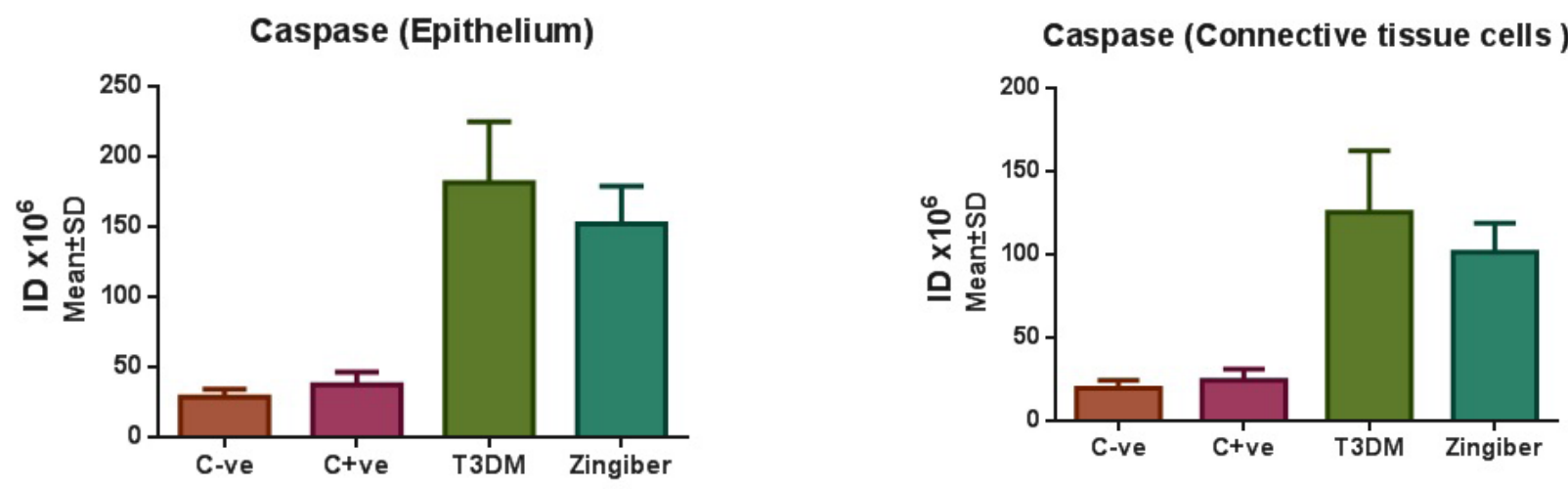

Fig. 8: Bar charts showing mean \pm SD of caspase-3 immunoreaction (Integrated density $x 10^{6}$ ) in epithelium and connective tissue cells among all studied groups 

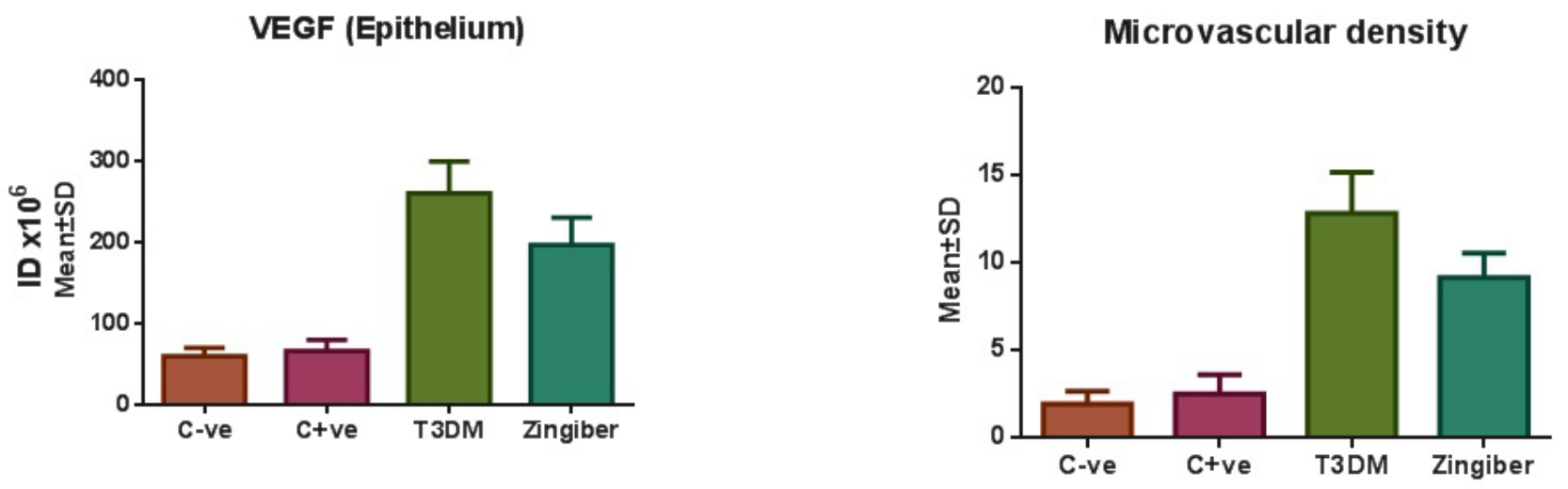

Wall thickness of blood vessels

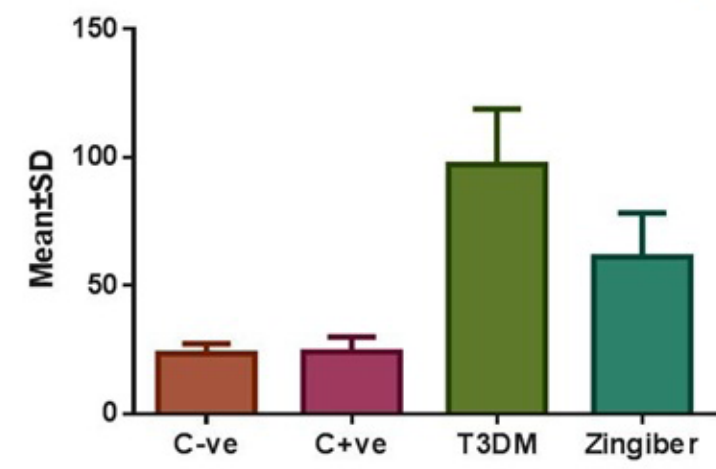

Fig. 9: Bar charts showing mean \pm SD of VEGF immunoexpression in epithelium (Integrated density $x 10^{6}$ ), microvascular density (Integrated density $x 10^{6}$ ) and wall thickness of blood vessels (In pixel) among all studied groups

\section{DISCUSSION}

Type 3 diabetes (T3DM) is a form of diabetes selectively occurs in the brain showing common characteristics with both types of diabetes mellitus (types 1 and 2) ${ }^{[28]}$. Since no relationship was inspected between insulin concentrations in brain, serum or in cerebrospinal levels ${ }^{[18]}$ along with the detected diverse distribution of insulin and insulin receptors in the brain. These findings provided the evidence for the different insulin sources peripherally versus the locally synthesized in brain for signal transduction ${ }^{[1,29]}$. Yet, the source of insulin in brain remains debated ${ }^{[30]}$. Streptozotocin (STZ), the nitrosamine-related compound was once injected ICV with a subdiabetogenic dose $(3 \mathrm{mg} / \mathrm{kg})$ in this work to simulate the environmental exposure to nitrosamines through smoking, diet and agriculture thus eliciting neurodegenerative changes and condition referred to as $\mathrm{T}^{2} \mathrm{DM}^{[31,32]}$. Since the available information about the histological changes of oral tissues in T3DM was very limited, this study aimed to investigate the T3DM-associated alterations of soft palatal mucosa in rats and to illustrate the effect of Zingiber extract oil on these alterations.

In this study, both the control-ve group as well as the control+ve group injected with saline intracerebroventricularly(ICV)presentedalmostsimilarhistopathological, fluorescence staining and immunohistochemical results with statistically insignificant difference.
The histopathological examination of brain tissues of both control groups elucidated regularly arranged normal neurons similarly to normal findings of Fang et al. ${ }^{[28]}$. While the brain tissues of T3DM specimens in this work displayed amyloid plaques five weeks after ICV-STZ injection that were investigated using congo red staining. The red to orange stained amyloid deposits were demonstrated along with the positively stained endothelium of the thickened cerebral blood vessels. Congo red is usually utilized because of its different affinities for nonfibrillar and fibrillar materials ${ }^{[25]}$ and for its higher sensitivity in differentiating amyloid from the other protein deposits ${ }^{[6]}$. In accordance with other reports ${ }^{[30]}$, we suggested that ICV-STZ injection rapidly increased free fatty acids, desensitized or damaged intracerebral insulin receptors and thus caused insulin signaling attenuation and resistance. These changes were considered as the direct causal factors and early features of T3DM. Qin et al. ${ }^{[32]}$ declared that insulin serves as a neuroprotective factor involved in diverse complex brain mechanisms such as regulation of amyloid beta protein $(A \beta)$ metabolism whereas the $A \beta$ itself was known as a natural antibiotic protecting the brain. However, insulin and $A \beta$ both were described as amyloidogenic peptides; $A \beta$ oligomers exhibited a binding affinity to insulin receptors exerting an antagonistic effect ${ }^{[28]}$. The subsequent decrease in glucose transporters plus utilization along with the impaired glucose and lipid metabolism would result in oxidative stress ${ }^{[18,29]}$ which in turn affect both production and 
clearance of $A \beta^{[28,30]}$. According to Revesz et al. ${ }^{[33]}$, cerebral amyloid angiopathy is characterized by amyloid deposition in the walls of cerebral blood vessels, but less often in capillaries, to reduce the strength of the vascular walls.

The histopathological findings of oral soft palatal mucosa in both control groups were concurrent with the results of Monroy et al..$^{[34]}$ and Hakami and Arthur ${ }^{[35]}$ studies. The soft palate oral epithelium appeared as thin less dense keratinized stratified squamous epithelium with large keratinocytes, bulky cytoplasm and often multiple nuclear lobes mostly in basal and spinous cell layers. Hayward et al. ${ }^{[36]}$ associated the high renewal rate of the oral epithelia in rat soft palate to the bilobed or tetraploid nuclei found in the keratinizing epithelium $^{[36]}$. In comparison to control groups, some H\&E sections of T3DM group demonstrated slightly thickened epithelium with inflammatory signs of basal, prickle and granular cells represented by cloudy swelling of epithelial cells that was considered as a reversible cell injury ${ }^{[37]}$. Furthermore, nuclear degenerative signs and intracytoplasmic vacuolation were also manifested along with apoptotic keratinocytes in basal and suprabasal cell layers. According to other reports ${ }^{[37,38]}$, we suggested that these epithelial changes resulted from the oxidative cell death mediated by the direct cytotoxic effect of $A \beta$ aggregates in amyloid related disorders like T3DM. Similarly, these histopathological alterations were also proved in the corneal epithelium of mice and were explained by the intracellular overexpression of APP together with the increased $A \beta$ deposition confirming the $A \beta$ toxicity to nearby cells via the induced oxidative stress and mitochondrial dysfunction in retina as well as in brain ${ }^{[39]}$. The evident subepithelial inflammation in lamina propria of this work was verified by the degenerative connective tissue areas, chronic inflammatory and giant cells infiltrates and congested dilated blood vessels with extravasation in the lamina propria of some specimens. In harmony with Joshi study ${ }^{[40]}$, these findings could contribute partly to the detected histopathological epithelial changes primarily in basal and parabasal keratinocytes including basilar hyperplasia in some areas. Alongside, the submucous palatine glands in turn showed pathologic changes included glandular hyperplasia, dilatation of acini and excretory duct analogous to those detected in other experimental rat studies ${ }^{[24,41]}$. Herein, the irregular appearance of the palatal fungiform papillae was displayed with a reduction in their distribution in addition to the vacuolation of few taste cells. In parallel, El-Sayyad et $a{ }^{[42]}$ attributed this comparable deformation following the maternal rat exposure to acrylamide residues to the direct cytotoxic effect on cell differentiation ${ }^{[42]}$. Most of the H\&E sections of Zingiber treated group revealed oral epithelium and lamina propria with features simulating those of control groups. Fewer areas elucidated some pathologic changes but to a lesser extent as compared to T3DM group such as clear cells in epithelium as well as inflammatory infiltrates in lamina propria. We ascribed the alleviation of T3DMassociated pathological alterations in this group to the therapeutic potentiality of Zingiber. In confirmation, Ahmed et $a l .{ }^{[16]}$ declared that the treatment of rats with Zingiber oil extract in a neurodegenerative study disclosed a significant improvement in the cellular structure via its free radical scavenging and anti-inflammatory properties. This influence was attained by the Zingiber active constituents like tannins, alkaloids and flavonoids which in turn inhibited the biosynthesis of leukotriene and prostaglandin inflammatory mediators and also suppressed macrophage activation and function $^{[14,16]}$.

The exploration of amyloid deposits was accomplished in this work as a parameter to assess the changes of the soft palate oral mucosa caused by $\mathrm{T} 3 \mathrm{DM}^{[10]}$. Thioflavin-T fluorochrome dye has been considered the gold standard fluorescent marker to identify amyloid deposition intra and extracellularly ${ }^{[25,43]}$. Amyloid fibrils stained with thioflavin-T are capable of transmitting and absorbing light producing a characteristic apple-green birefringence when visualized under fluorescence microscope because of its metachromatic properties with the aniline dy $\mathrm{e}^{[6]}$. Both control groups exhibited apparent faint to mild thioflavin-T fluorescence in the basal and parabasal oral epithelial cell layers, basal and cellular membranes of submucous glandular acini as well as in the endothelium of blood vessels. Keratin was positively stained for thioflavin-T as usually reported ${ }^{[44]}$. Some reports asserted that the amyloid precursor protein (transmembrane protein) isoforms were expressed in peripheral tissues (almost all body cells) and also have mitogenic, motogenic and cell-cell adhesion function in keratinocytes. Thus, different body cells contributed to the production of the circulating $\mathrm{A} \beta^{[12,33,45]}$. T3DM sections displayed statistically significant different results comparing to control groups. In some sections, diffuse strong membranous and intracellular fluorescence was detected in basal and some suprabasal epithelial cell layers as well as in the palatine acinar cells. In explanation of these findings, the cerebral amyloid deposits in a neurodegenerative condition like T3DM were evidenced to be associated with increased $\mathrm{A} \beta$ levels shown in peripheral tissues such as skin, skeletal muscle, heart, liver and thyroid secondary to the abnormal calcium fluxes and overexpression of pathogenic APP form resulting in defective oxidative metabolism ${ }^{[12,33,46]}$. The mitochondrial alterations along with reduced ATP levels were associated with intracellular A-aggregates which preceded the extracellular $\mathrm{A} \beta$ deposition $^{[47]}$. These impairments indicated the reduced extracellular $A \beta$ clearance and also enhanced the further nonspecific release and deposition of $A \beta$ aggregates from damaged membranes, endosomal-lysosomal breakdown, discharge of vesicular contents and thus accelerating APP proteolysis ${ }^{[30,48]}$. In concurrence to Kumakiri and Hashimoto $^{[49]}$, some strongly fluorescent subepithelial $\mathrm{A} \beta$ deposits were also noticed. Some authors described these deposits ultrastructurally as electron-dense parts contained tightly packed filaments as well as macrophages or fibroblasts that may be found among these islands ${ }^{[49]}$. Comparing to control groups, we also observed a significant strong thioflavin-T fluorescence in the vascular walls of the significantly increased blood vessels in thickness and distribution in the lamina propria. In confirmation to these results, some investigators correlated the altered levels of $\mathrm{A} \beta$ in plasma and blood along with the overproduction of 
$\mathrm{A} \beta$ in endothelial cells, endothelial enlargement, vascular proliferation, changes of vascular tone and endothelial cell function to the $A \beta$ dysregulation-mediated vascular disease ${ }^{[46,50]}$. The increased accumulation of $A \beta$ and APP peripherally supported the hypothesis that $A \beta$ diseases could be systemic either the proteins produced locally in different tissues or produced from the same circulating precursor ${ }^{[7,47]}$. In this work, the Zingiber treated group demonstrated a statistically significant restoration of the detected T3DM alterations so that mild to moderate fluorescence was distinguished in the soft palate oral epithelial cells, vascular endothelium and acinar cells of palatal glands. These results supported the histopathological findings and reflected that the Zingiber effect was sufficient to considerably interfere with fluorescence signal production defining Zingiber as anti-amyloid candidate ${ }^{[13]}$. Zingiber flavonoids and polyphenols denoted anti-aggregatory and antioxidant properties through disintegration of most amyloid plaques, attenuation of intracellular $A \beta$ oligomers deposition ${ }^{[51]}$ and restoration of the depleted endogenous antioxidants ${ }^{[38]}$.

In the current work, caspase- 3 expression was evaluated in the soft palate oral keratinocytes and underlying connective tissue cells to assess apoptosis. Apoptosis, a genetically regulated cell suicide mechanism mostly affect the nucleus and characterized by cell shrinkage with intact membrane, chromatin condensation, nuclear pyknosis and DNA fragmentation ${ }^{[52]}$. The widely known functions of caspases vary from the cell death regulation to other multiple physiological processes ${ }^{[53]}$. Caspase- 3 is one of the pro-apoptotic effector caspases which cleaves nucleases and cellular substrates disabling cellular processes and eventually causing cell death ${ }^{[52]}$. Veeravarmal et al. ${ }^{[54]}$ added that caspase- 3 executed apoptosis is initiated either through the stimulation of intrinsic death receptor (independent mitochondrial pathway) or through extrinsic transmembrane death receptor (dependent pathway). The cytoplasmic localization of caspase-3 corresponded to procaspase-3 locality while the nuclear accumulation of caspase- 3 if detected possibly due to the nuclear translocation of caspase-3 $3^{[27,55]}$. Numerous studies illustrated similar caspase-3 results in normal oral epithelium ${ }^{[27,56]}$ akin to the control groups in this work and affirmed that apoptosis was strictly regulated throughout the keratinization process. In comparison, some T3DM specimens of our work exhibited a significant heterogeneous immunoreactivity to caspase- 3 varied from diffuse mild/moderate to focal strong cytoplasmic reactivity across the slightly thickened epithelial layers and in the vacuolated intraepithelial taste cells. Apparently increased apoptotic keratinocytes were identified by brown granules in the positive nuclei of the apoptotic cells ${ }^{[57]}$ along with the significant increase of caspase-3 positive connective tissue cells including fibroblasts and inflammatory cells. In synchronization, some studies of the amyloid related disorders assigned the observed degenerative foci in keratinocytes to the $A \beta$ cytotoxicity that rendered the cells more susceptible to diverse exogenous insults ${ }^{[38]}$. Caspase- 3 activation was mediated by cleavage of APP ${ }^{[58]}$ since amyloid fibrils could disrupt cellular membranes along with receptors either by their hydrophobic surface which interacts with the lipid bilayer or by getting physically large enough. Thus, the induced inflammatory response itself may promote the clearance of aggregated peptides or else it may elicit the release of inflammatory cytokines causing cellular disruption and then apoptosis ${ }^{[51]}$. Additionally, some studies correlated apoptosis in the oral epithelia with the subepithelial inflammatory infiltrates in the lamina propria such as macrophages which engulf degenerated cells in amyloidosis disorders. Therefore, the consequent release of proinflammatory cytokines such as TNF- $\alpha$ could influence the epithelial function ${ }^{[49,59,60]}$ and cell damage by caspase-3 activation $^{[28,30]}$. Furthermore, caspase-3 was reported to be activated in hypoxia and thus associated with the increase of apoptotic cells that ultimately fragmented into apoptotic bodies to be phagocytosed ${ }^{[54,56]}$. Comparing to T3DM group, some specimens of Zingiber treated group in the present work showed similarity to control groups with apparent decrease of apoptotic keratinocytes. In confirmation, Zeng et al..$^{[61]}$ and Ahmed et al. ${ }^{[16]}$ stated the possible protective antiapoptotic, anti-hypoxic as well as antioxidant potentiality of Zingiber extract on $A \beta$ associated apoptosis through the resolution of the resultant pathogenic alterations correlated with some neurodegenerative diseases. This improvement was also evident and confirmed in the previous histological and fluorescence results of this work. Yet, some Zingiber specimens also showed a low significant decrease of caspase-3 reactivity in oral epithelium, intraepithelial taste bud cells as well as inflammatory infiltrates in the underlying lamina propria. In parallel to other reports ${ }^{[59,62]}$, we ascribed these results to the influence of Zingiber in the amelioration of inflammatory changes caused by T3DM. Accordingly, Brant et $a l .{ }^{[59]}$ found that apoptosis was involved in the resolution of inflammatory changes and was responsible for inflammatory cells elimination when inflammation declines. Thus, increased apoptosis within the inflammatory infiltrates indicated for less inflammation as well as fewer apoptotic cells in the oral epithelium ${ }^{[59]}$.

Vascular endothelial growth factor (VEGF) is involved in maintenance and development of the vascular system. It is secreted by most cell types and binds to their cognate receptors in endothelial and other cells to elicit various effects. It afforded a tool to study both epithelial and vascular changes in normal and diseased tissues ${ }^{[63-66]}$. In concurrent with some studies, the low VEGF expression detected in the control groups of our work was explained by that VEGFR signaling is involved in the proliferation and migration of normal keratinocytes and thus regulate mucosal function ${ }^{[67,68]}$. Nakanishi et al..$^{[65]}$ added that the soluble VEGF released from proliferating differentiating keratinocytes as well as the insoluble VEGF associated with the more differentiated cells, enhanced vascularization. Likewise, the turnover rate of the quiescent endothelial cell population in resting bloods vessels is extremely low ${ }^{[67]}$. Comparing to control groups, some T3DM specimens illustrated a significantly increased nuclear and heterogeneous cytoplasmic reaction to VEGF in the palatal oral epithelial cells and some intraepithelial taste cells. This reaction was mild in the 
cloudy swollen and apoptotic keratinocytes. Similar to Gupta et al. ${ }^{[69]}$ study, we suggested that the alterations of VEGF immunolocalization reflected its involvement in the progression of inflammatory changes following the T3DMassociated $A \beta$ aggregates in epithelial cells. It was declared that oxidants prominently enhanced the upregulation of VEGF in oral keratinocytes as a consequence of either cytokines secretion or direct activation of the transcriptional pathways suggesting that epithelial VEGF may be regulated by redox control ${ }^{[65,68]}$. Some authors confirmed the direct implication of $A \beta$ aggregates in the upregulation of VEGF in association with amyloid angiopathy, vasoconstriction and tissue hypoxia in addition to the higher affinity of VEGF to bind $A \beta$ rather than its own receptors ${ }^{[70]}$. Meanwhile, T3DM group of this study showed a significant increase of VEGF positivity in the endothelium of the significantly increased blood vessels in wall thickness and distribution. Analogous to other investigations ${ }^{[70]}$, we significantly correlated both angiopathy and microvessel density to the A $\beta$ correlated VEGF upregulation. Nakanishi et al. ${ }^{[65]}$ believed that VEGF significantly regulates inflammatory response via active angiogenesis in various pathologic and hypoxic conditions ${ }^{[71]}$. Angiogenesis contributes to the degree of chronic inflammation as VEGF influences microvascular permeability contributing to the transport of proinflammatory cells as well as the supply of nutrients and oxygen to inflamed tissues ${ }^{[72]}$ along with endothelial cell migration, proliferation and differentiation via autocrine or paracrine mechanisms ${ }^{[65,73]}$. Likewise, the endothelial nitric oxide production induced by VEGF elicited vasodilatation of blood vessels, recruitment of inflammatory infiltrates such as macrophages that contributed to the further production of VEGF. VEGF was also implicated in the pericellular matrix degradation via the increase of the proteases expression at the neovascularized inflammation sites ${ }^{[26,71,72]}$.

The Zingiber treated group manifested a significant decrease of VEGF immunoreactivity comparing to T3DM group in epithelial cells, taste bud cells and in the endothelium of the significantly decreased blood vessels in distribution and wall thickness. In agreement with the observed amelioration of T3DM changes in this group, Mahdy et al. ${ }^{[74]}$ asserted that the antioxidant property of ginger extract selectively attenuated the production of pro-inflammatory cytokines by macrophage and also increase the activity of glutathione peroxidase in rats. Nakanishi et al ${ }^{[65]}$ attributed the reduced VEGF expression in epithelium to the increase of epithelial differentiation following tissue repair ${ }^{[65]}$ while the obvious VEGF reaction in some epithelial cells of this group most likely ascribed to the increased APP expression in the less/ undifferentiated keratinocytes as reported in mice studies ${ }^{[45]}$. Furthermore, Ruiz et al. ${ }^{[26]}$ showed that the low expression of VEGF reflected the low level of inflammation subsequent to the reduced antigenic stimulation. In addition, the authors positively correlated the VEGF immunoexpression and microvascular density with the intensity of inflammatory infiltrates that showed a low significant decrease in this group by apoptosis as previously mentioned in this work.
It was concluded that T3DM caused progressive neurodegenerative changes that simulated those of Alzheimer's disease according to some authors who proposed "Type3 DM" as Alzheimer's disease ${ }^{[1]}$. T3DM caused oral mucosal alterations that were primarily resulted from the toxic $A \beta$-associated oxidative stress. The oil extract of Zingiber officinale roscoe was a properly selected approach for ameliorating these changes. Zingiber was more potent in sequestering the amyloid aggregates than in downregulating VEGF activity and least for caspase-3 activity in this study. This may indicate the need for a higher dose or prolonged supplementation of Zingiber particularly due to its obvious therapeutic potentiality in managing the possibly T3DM-associated peripheral tissue insults.

\section{DATA AVAILABILITY}

"All data underlying the results are available as part of the article and no additional source data are required."

\section{ABBREVIATIONS}

(T3DM): Type3 diabetes mellitus, (ICV): intracerebroventricular, (STZ): streptozotocin, (A $\boldsymbol{\beta})$ : amyloid beta protein, (APP): amyloid precursor protein, (H\&E): Hematoxylin and Eosin, (VEGF): vascular endothelial growth factor

\section{CONFLICTS OF INTEREST}

There are no conflicts of interest.

\section{REFERENCES}

1. Kandimalla $\mathrm{R}$, Thirumala $\mathrm{V}$ and Reddy $\mathrm{PH}$ : Is Alzheimer's disease a Type 3 Diabetes? A critical appraisal. Biochimica et Biophysica Acta. (2017) 1863: 1078-1089.

2. Mishra SK, Singh S, Shukla S and Shukla R: Intracerebro-ventricular streptozotocin impairs adult neurogenesis and cognitive functions via regulating neuroinflammation and insulin signaling in adult rats. Neurochemistry International. (2018) 113: $56-68$.

3. Martínez JO, Salazar RC, Requena C, Tost M and Lluch A: Alzheimer's disease: oral manifestations, treatment and preventive measures. J Oral Res. (2014) 3(3): 184-189.

4. Hattori $\mathrm{H}$, Matsumoto $\mathrm{M}$, Iwai $\mathrm{K}$, Tsuchiya $\mathrm{H}$, Miyauchi E and Takasaki M et al.: The T Protein of Oral Epithelium Increases in Alzheimer's Disease. Journal of Gerontology medical sciences. (2002) (57A) 1: 64-70.

5. Gunhan O, Celasun B, Perrini F, Covani U, Perrini N, Ozdeinir A, Bostanci H and Finci R: Generalized gingival enlargement due to accumulation of amyloid-like material. J. Oral Pathol. Med. (1994) 23: 423-8. 
6. Asúa DR, Costa R, Galván JM, Trujillo MTFD and Cadiñanos J: Systemic AA amyloidosis: epidemiology, diagnosis, and management. Clinical Epidemiology. (2014) 6 369-377.

7. Li S, Liu B, Zhang L and Rong L: Amyloid beta peptide is elevated in osteoporotic bone tissues and enhances osteoclast function. Bone. (2014) 61: 164-175.

8. Westen DV, Jeromin A, Song L, Hanlon D and Hehir CAT et al:: Plasma $\beta$-amyloid in Alzheimer's disease and vascular disease. Sci. Rep. (2016) May 31; 6: 26801.

9. Prasansuklab A and Tencomnao T: Amyloidosis in Alzheimer's Disease: The Toxicity of Amyloid Beta (A-), Mechanisms of Its Accumulation and Implications of Medicinal Plants for Therapy. Evidence-Based Complementary and Alternative Medicine. (2013) 413808:10 pages.

10. Seo EJ, Fischer $\mathrm{N}$ and Efferth T: Phytochemicals as inhibitors of NF- $\mathrm{kB}$ for treatment of Alzheimer'sdisease. Pharmacol Res. (2018) 129:262-273.

11. Jevtica S, Sengarb AS, Salterb MW and McLaurin $\mathrm{J}$ : The role of the immune system in Alzheimer disease: Etiology and treatment. Ageing Research Reviews. (2017) 40: 84-94.

12. Camargo LC, Campos GAA, Galante P, Biolchi AM, Gonçalves JC, Lopes KS and Mortari MR: Peptides isolated from animal venom as a platform for new therapeutics for the treatment of Alzheimer's disease. Neuropeptides. (2018) 67:79-86.

13. Choia JG, Kimb SY, Jeongb $M$ and $\mathrm{Oh}$ MS: Pharmacotherapeutic potential of ginger and its compounds in age-related neurological disorders. Pharmacology and Therapeutics. (2018) 182: 56-69.

14. Mahmoud SM and Abdel Moneim AE: Zingiber methanolic extract (ZME) of dry ginger powder mitigates potassium dichromate-neurotoxicity in rat brain. World Journal of Pharmaceutical Research. (2018) 7(18): 296-321.

15. Ho SC, Chang KS and Lin CC: Anti-neuroinflammatory capacity of fresh ginger is attributed mainly to 10-gingerol. Food Chemistry. (2013) 141: 3183-3191.

16. Ahmed HH, Zaazaa AM and Abd El-Motelp BA: Zingiber officinale and Alzheimer's Disease: Evidences and Mechanisms. Int. J. Pharm. Sci. Rev. Res. July - August (2014) 27(2), 21: 142-152.

17. Bassania TB, Turnesa JM, Mouraa ELR, Bonatob JM, Segoviac VC, Zanatac SM, Oliveirab RMMW and Vitala MABF: Effects of curcumin on short-term spatial and recognition memory, adult neurogenesis and neuroinflammation in a streptozotocin- induced rat model of dementia of Alzheimer's type. Behavioural Brain Research. (2017) 335: 41-54.

18. Grieb P: Intracerebroventricular Streptozotocin Injections as a Model of Alzheimer's Disease: in Search of a Relevant Mechanism. Mol. Neurobiol. (2016) 53:1741-1752.

19. Correia SC, Santos RX, Santos MS, Casadesus G, LaManna JC, Perry G, Smith MA and Moreira PI : Mitochondrial Abnormalities in a StreptozotocinInduced Rat Model of Sporadic Alzheimer's Disease. Current Alzheimer Research. (2013) 1;10(4):406-19.

20. Radwan NM: Effect of Taurine on the EEG-Power Spectrum in the Pilocarpine-Model of Epilepsy. J. Egypt. Ger. Soc. Zool. (2001) 36 (A): 29-49.

21. Coll NL, Rivera EJ, Soscia SJ, Doiron K and Jack R.: Wands and Suzanne M. de la Monte: Intracerebral streptozotocin model of type 3 diabetes: Relevance to sporadic Alzheimer's disease. Journal of Alzheimer's Disease. (2006) 9:13-33.

22. Abdel Moneim RA, El Deeb M and Saad F A: Evaluation of the therapeutic potential of Tamarind seeds (Aqueous extract) versus antidiabetic drugs on the histological structure of lingual papillae in diabetic rats. E.D.J. (2018) July, (64): 603-620.

23. Fang F, Yan N, Feng Z, Liu X, Xiao Z, Wen M, Huang $\mathrm{H}$ and Yan Y: Alzheimer's disease Animal Model by Aluminum, Beta-Amyloid and Transforming Growth Factor Beta-1. Aging and Neurodegeneration, September (2013) 1(1): 15-19.

24. Deveci I, Sürmeli M, Deveci SH, Eriman M, Habesoglu M, Tek A, Misirlioglu K and Gunes P: Effects of polycystic ovary syndrome and menopause on rat soft palate and base of tongue. Otolaryngol Head Neck Surg. Apr (2013) 148 (4):595-601.

25. Picken MM and Herrera GA: Thioflavin T Stain: An Easier and More Sensitive Method for Amyloid Detection. Amyloid and Related Disorders. (2012) 187-189.

26. Ruiz PA, Toledo OA, Nonaka CFW, Pinto LP and Souza LB: Immunohistochemical expression of vascular endothelial growth factor and matrix metalloproteinase-9 in radicular and residual radicular cysts. J Appl Oral Sci. (2010) 18(6): 613-20.

27. Maraeea AH, El-Rebeyb HS and Zakya EA: Caspase-3 expression in lichen planus. Menoufia Medical Journal. (2016) 29: 396 - 405.

28. Pardeshia R, Bolshetteb N, Gadhavec K, Ahirec A, Ahmed $\mathrm{S}$ and Cassanod Tet al.: Insulin signaling: An opportunistic target to minify the risk of Alzheimer's Disease. Psychoneuroendocrinology. (2017) 83: 159-171. 
29. Gru“ nblatt E, Petrisic MS, Osmanovic J, Riederer $\mathrm{P}$ and Hoyer S: Brain insulin system dysfunction in streptozotocin intracerebroventricularly treated rats generates hyperphosphorylated tau protein. Journal of Neurochemistry. ( 2007) 101: 757-770.

30. SilzeraTK and Phillipsa NR: Etiology of type 2 diabetes and Alzheimer's disease: Exploring the mitochondria. Mitochondrion. (2018) Nov, 43: 16-24.

31. Shaw K: Type 3' diabetes: a brain insulin-resistant state linked to Alzheimer's disease. July/August (2017 ) 34(6): 187-188.

32. Qin L, Chun WS and Kan D: Research advances in the treatment of Alzheimer's disease with polysaccharides from traditional Chinese medicine. Chinese journal of natural medicines. (2017)15(9): 0641-0652.

33. Revesz T, Ghiso J, Lashley T, Plant G, Rostagno A, Frangione B, and Holton J: Cerebral Amyloid Angiopathies: A Pathologic, Biochemical, and Genetic View. Journal of Neuropathology and Experimental Neurology. (2003) 62, 9: 885-898.

34. Monroy PLC, Grefte S, Jagtman AMK, Helmich MPAC and Ulrich DJ et al:: A rat model for muscle regeneration in the soft palate. PLoS ONE. (2013) 8(3): e59193.

35. Hakami Z and Hand AR: Developmental Morphology of the Palatine Glands in Rats: An Electron Microscope Study. The anatomical record. (2018) 301:1820-1833.

36. Hayward AF, Hamilton AI and Hackemann MA: Histological and ultrastructural observations on the keratinizing epithelia of the palate of the rat. Arch oral Biol. Aug (1973) 18(8):1041-57.

37. Hayes AW: Principles and Methods of Toxicology Fourth Edition, Raven Press, New York, (2001) and $5^{\text {th }}$ edition (2008).

38. Lee C, Park GH, Kim CY and Jang JH : [6]-Gingerol attenuates b-amyloid-induced oxidative cell death via fortifying cellular antioxidant defense system. Food and Chemical Toxicology. (2011) 49: 1261-1269.

39. Zhizhang D, Ali L, Yifeng G and Juan L: Amyloid beta deposition could cause corneal epithelial cell degeneration associated with increasing apoptosis in APPswePS1 transgenic mice. Curr Eye Res. Nov (2018) 43(11):1326-1333.

40. Joshi R: Interface dermatitis. Indian J Dermatol Venereol Leprol. May-June (2013) 79, 3: 349-359.

41. Habesoglu TE, Habesoglu M, Sürmeli M, Deveci I, Toros SZ and Gunes Pet al.: Histological changes of rat soft palate with exposure to experimental laryngopharyngeal reflux. Auris Nasus Larynx. (2010) 37: 730-736.

42. El-Sayyad HIH, Khalifa SA, Fahmy AAE, El-Shahary EA and Ibrahim EMA: Abnormal soft palate, lingual mucosa and intestine of neonates maternally fed on diet containing fried potatoes chips or received acrylamide-treatment. J Pharma Reports. (2017) 2:3.

43. Chiu YH, Chen PJ, Chang YM and Hou TY: Gastrointestinal Amyloidosis in a Patient with Systemic Sclerosis. J Med Sci. (2017) 37,3: 117-119.

44. Biancalana M and Koide S: Molecular Mechanism of Thioflavin-T Binding to Amyloid Fibrils. Biochim Biophys Acta. (2010) July; 1804(7): 1405-1412.

45. Kummer C, Wehner S, Quast T, Werner S and Herzog $\mathrm{V}$ : Expression and potential function of $\beta$-amyloid precursor proteins during cutaneous wound repair. Experimental Cell Research. (2002) 280: 222-232.

46. Janelidze S, Stomrud E, Palmqvist S, Zetterberg H, Westen DV and Jeromin A et al.: Plasma $\beta$-amyloid in Alzheimer's disease and vascular disease. Sci Rep. May (2016) 6:26801.

47. Schuh R, Jackson KC, Schlappal AE, Spangenburg EE, Ward CW and Park JH et al.: Mitochondrial oxygen consumption deficits in skeletal muscle isolated from an Alzheimer's disease-relevant murine model. BMC Neuroscience. (2014) 15:24.

48. Querfurth HW and Selkoe DJ: Calcium Ionophore Increases Amyloid p Peptide Production by Cultured Cells?. Biochemistry. (1994) 33: 4550-4561.

49. Kumakiri $\mathrm{M}$ and Hashimoto $\mathrm{K}$ : Histogenesis of primary localized cutaneous amyloidosis: sequential change of epidermal keratinocytes to amyloid via filamentous degeneration. The journal of investigative dermatology. (1979) 73, 2:150-152.

50. Retana SF, Montañola A, Marazuela P, La Cuesta M, Batlle A and Fatar $\mathrm{M}$ et al.: Intravenous treatment with human recombinant ApoA-I Milano reduces beta amyloid cerebral deposition in the APP23transgenic mouse model of Alzheimer's disease. Neurobiology of Aging. (2017) 60: 116-128.

51. Ficulleb ME, Piccolob L, Corbob M and Feligionia M: An overview of the possible therapeutic role of sumoylation in the treatment of alzheimer's diseases. Pharmacol Res. Apr (2018)130:420-437.

52. Taha NS: Effect of glucocorticoids alone or in combination with h1 receptor antagonist on rat sub mandibular salivary glands. E.D.J. (2015) 61:4999:5008.

53. Li J and Yuan J: Caspases in apoptosis and beyond. Oncogene. (2008) 27, 6194-6206. 
54. Veeravarmal V, Austin RD, Siddavaram N, Thiruneelakandan S and Nassar MH: Caspase-3 expression in normal oral epithelium, oral submucous fibrosis and oral squamous cell carcinoma. J. Oral Maxillofac. Pathol. Sep-Dec (2016) 20, 3:445-452.

55. Wichapoon B, Punsawad C and Viriyavejakul $\mathrm{P}$ : Expression of cleaved caspase-3 in renal tubular cells in Plasmodium falciparum malaria patients. Nephrology (Carlton). Jan (2017) 22(1):79-84.

56. Loro LL, Vintermyr OK and Johannessen AC: Apoptosis in normal and diseased oral tissues. Oral Diseases. (2005) 11: 274-287.

57. Shuxia Li, Yang Y, Ding Y, Tang $X$, and Sun $\mathrm{Z}$ : Impacts of survivin and caspase-3 on apoptosis and angiogenesis in oral cancer. Oncol Lett. 2017 Sep; 14(3): 3774-3779.

58. Mcilwain DR, Berger T and Mak TW: Caspase functions in cell death and disease. Cold Spring Harb Perspect Biol. April ( 2015) 7(4):a008656.

59. Brant JM, Aguiar MC, Grandinetti HA, Rodrigues LV and Vasconcelos AC: A comparative study of apoptosis in reticular and erosive oral lichen planus. Braz Dent J. (2012) 23(5):564-9.

60. Bruewer M, Luegering A, Kucharzik T, Parkos CA and Madara JL et al:: Proinflammatory cytokines disrupt epithelial barrier function by apoptosis-independent mechanisms. J Immunol. Dec (2003) 1;171(11):6164-72.

61. Zeng GF, Zong SH, Zhang ZH, Fu SW, Li KK, Fang Y, Lu L and Xiao DQ: The role of 6-gingerol on inhibiting amyloid $\mathrm{b}$ protein-induced apoptosis in PC12 Cells. Rejuvenation Res. Oct (2015) 18(5): 413-21.

62. Bulut S and O" zdemir BH: Apoptosis and Expression of Caspase-3 in Cyclosporin-Induced Gingival Overgrowth. J Periodontol. Dec (2007 ) (78) 12:2364-8.

63. Karaman S, Leppanen VM and Alitalo K: Vascular endothelial growth factor signaling in development and disease. Development. (2018) 145(14) dev151019.

64. Astekar M, Joshi A, Ramesh G, Metgud $\mathrm{R}$ : Expression of vascular endothelial growth factor and microvessel density in oral tumorigenesis. Journal of Oral and Maxillofacial Pathology. Jan -
Apr (2012) 16 (1):22-6.

65. Nakanishi Y, Izumi K, Yoshizawa $M$, Saito C, Kawano $\mathrm{Y}$ and Maeda $\mathrm{T}$ : The expression and production of vascular endothelial growth factor in oral mucosa equivalents. Int. J. Oral Maxillofac. Surg. (2007) 36: 928-933.

66. Shibuya M: Vascular Endothelial Growth Factor (VEGF) and Its Receptor (VEGFR) Signaling in Angiogenesis: A Crucial Target for Anti- and Pro-Angiogenic Therapies. Genes \& Cancer. (2011) 2(12): 1097-1105.

67. Tae K, El-Naggar AK, Yoo E, Feng L, Lee JJ, Hong WK, Hittelman WN and Shin DM: Expression of vascular endothelial growth factor and microvessel density in head and neck tumorigenesis. Clin Cancer Res. Jul (2000) 6(7):2821-8.

68. Bae ON, Noh M, Chun YJ and Jeong TC: Keratinocytic Vascular Endothelial Growth Factor as a Novel Biomarker for Pathological Skin Condition. Biomol Ther. (2015) 23(1): 12-18.

69. Gupta S, Gupta V, Tyagi N, Vij R, Vij H and Sharma $\mathrm{E}$ : analysis of role of angiogenesis in epithelial dysplasia: an immunohistochemical study. Journal of clinical and diagnostic research - December (2017) 11(12): 29-34.

70. Harris R, Miners JS, Allen S and Love S: VEGFR1 and VEGFR2 in Alzheimer's Disease. Journal of Alzheimer's Disease. (2018) 61: 741-752.

71. Tammela T, Enholm B, Alitalo K and Paavonen $\mathrm{K}$ : The biology of vascular endothelial growth factors. Cardiovascular Research. (2005) 65: $550-563$.

72. Güner P, Ünlü F, Yesilbek B, Bayraktar F, Kokuludag A, Hekimgil $M$ and Boyacioglu $\mathrm{H}$ : Vascular Endothelial Growth Factor in Gingival Tissues and Crevicular Fluids of Diabetic and Healthy Periodontal Patients. J Periodontol. January (2004) 75(1): 91-97.

73. Marti HH: Vascular Endothelial Growth Factor. Austin (TX): Landes Bioscience; 2000-2013 (2013).

74. Mahdy KA, Gouda NAM, Marrie AH, Yassin NAZ and El-Shenawy SMA et al:: Protective Effect of Ginger (Zingiber officinale) on Alzheimer's disease Induced in Rats. J Neuroinfect Dis. (2014) 5:2. 


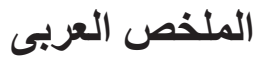

\section{تأثير الزنجبيل الطبي على التغيرات الهستولولوجية للغثاء المخاطي لسقف الحلق الرخو فى داء السكري النوع 3 المستحث بالستربتوزوتوسين في نموذج الجرذ \\ فاطمة عادل سعد}

مدرس بيولوجيا الفم- جامعة المستقبل - مصر

نبذة مختصرة: يقدم الزنجبيل نتائج مفيدة في بعض الأمر اض التنكسية العصبية الهدف من التجربة : هدفت هذه الدر اسة إلى تقييم فاعلية مستخر اج زيت الزئن الزبيل في تر اجع داء السكري من النوع 3 المستحث في نموذج الفئر ان. التجربة: تم تقسيم 28 من الفئر ان البيضاء الذكور البالغين إلى أربعة مجمو عات منساوية:

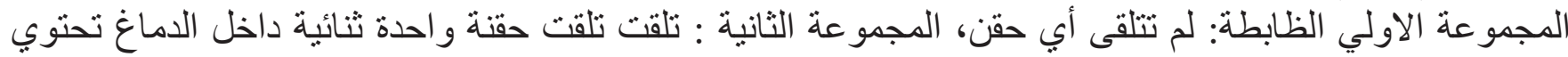

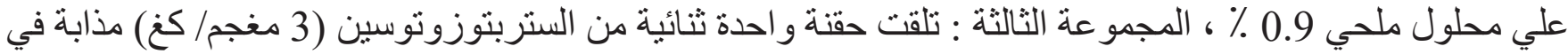

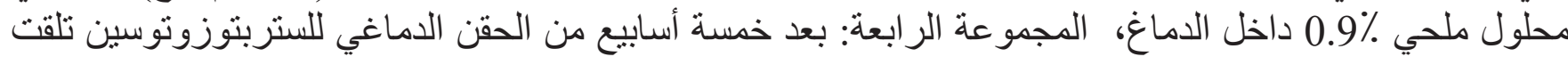
المجمو عة 100 ملجم / كجم من مستخلص زيت الزنجبيل كل يوم عن طريق الفم لمدة شهرين ـ تمت معالجة عينات

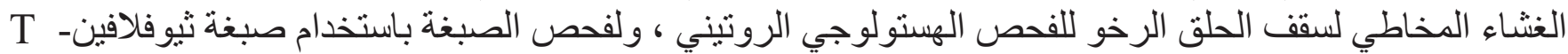

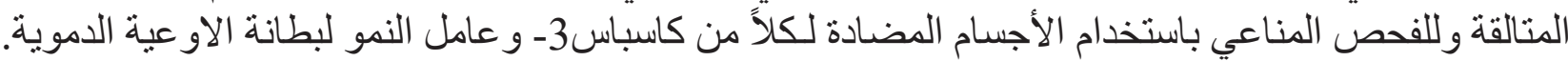

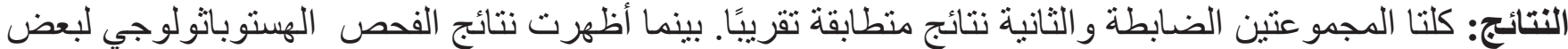

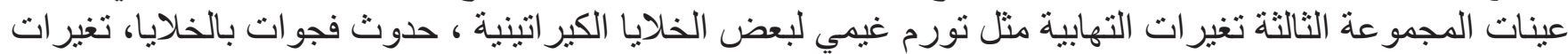
انحلالية بالانوية بالاضافة الي زيادة في الاجسام الناتجة عن الموت الخلوي ، مناطق تنكسية تحت الظهارة، تسلل

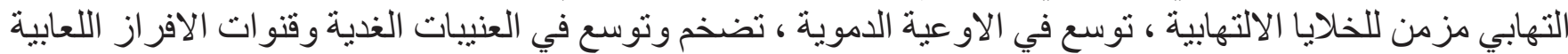
ـ وبالنسبة للحليمات الكمئية الفطرية بسقف الحلق الرخو فظهرت بمظهر غير منظم في الثكل مع قلة عددهم الي جانب

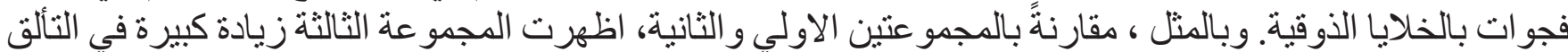

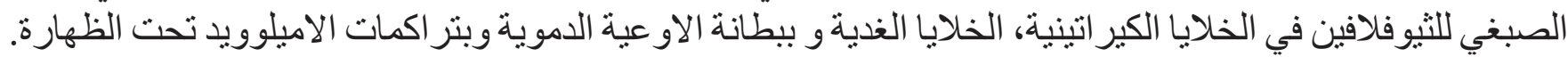
وجدت زيادة كبيرة في التفاعل المناعي بالمجموعة الثالثة لكاسباس3- بالخلايا الكير اتتية وخلايا النسيج الضام وأيضاً

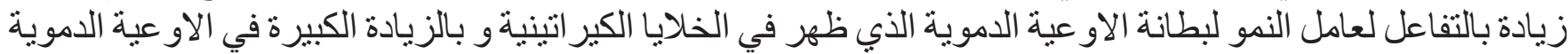

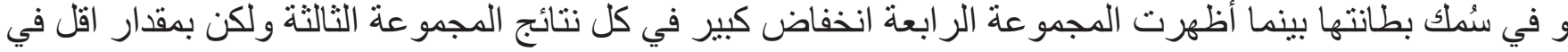
كاسباس 3-

الاستتتاج: ومما سبق تم إستنتاج أن مستخلص زيت الزنجبيل كان منهجًا مناسبًا مختارًا لتحسين التغيرات التنكسية

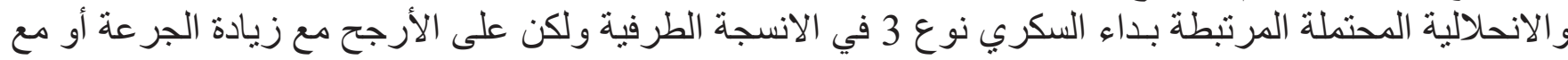
تناو له لفتر ات مطولة. 